\title{
A Learning Health System Randomized Trial of Monoclonal Antibodies for Covid-19
}

Erin K. McCreary PharmD ${ }^{1}$, J. Ryan Bariola MD ${ }^{1}$, Tami Minnier MS ${ }^{2}$, Richard J. Wadas MD ${ }^{3}$, Judith A. Shovel BSN ${ }^{2}$, Debbie Albin $\mathrm{BS}^{4}$, Oscar C. Marroquin $\mathrm{MD}^{5}$, Kevin E. Kip PhD Kevin Collins MBA ${ }^{5}$, Mark Schmidhofer MD ${ }^{6}$, Mary Kay Wisniewski, MA², David A Nace $\mathrm{MD}^{7}$, Colleen Sullivan MHA ${ }^{8,11}$, Meredith Axe BS ${ }^{3}$, Russell Meyer MBA ${ }^{3}$, Alexandra Weissman $\mathrm{MD}^{3}$, William Garrard $\mathrm{PhD}^{5}$, Octavia M. Peck-Palmer PhD ${ }^{9}$, Alan Wells MD DMS ${ }_{\mathrm{c}}{ }^{9}$, Robert D. Bart MD ${ }^{10,13}$, Anne Yang MD ${ }^{14}$, Lindsay Berry $\mathrm{PhD}^{15}$, Scott Berry PhD ${ }^{15}$, Amy Crawford $\mathrm{PhD}^{15}$, Anna McGlothin, $\mathrm{PhD}^{15}$, Tina Khadem PharmD ${ }^{11}$, Kelsey Linstrum $\mathrm{MS}^{8,11}$, Stephanie K. Montgomery MS ${ }^{8,11}$, Daniel Ricketts $\mathrm{MT}^{8}$, Jason N. Kennedy MS ${ }^{8,13}$, Caroline J. Pidro BS ${ }^{8}$, Ghady Haidar MD ${ }^{1}$, Graham M. Snyder MD ${ }^{1}$, Bryan J. McVerry, MD ${ }^{12}$, Derek C. Angus MD, MPH ${ }^{8,11,13}$, Paula L. Kip PhD², Christopher W. Seymour MD, MSc ${ }^{8,11,13}$, David T. Huang MD, $\mathrm{MPH}^{3,8,13^{*}}$

\section{AFFILIATIONS}

1. Division of Infectious Diseases, Department of Medicine, University of Pittsburgh School of Medicine, Pittsburgh, PA, USA

2. Wolff Center, UPMC, Pittsburgh, PA, USA

3. Department of Emergency Medicine, University of Pittsburgh School of Medicine, Pittsburgh, PA, USA

4. Supply Chain Management/HC Pharmacy, UPMC, Pittsburgh, PA, USA

5. Clinical Analytics, University of Pittsburgh Medical Center, Pittsburgh, PA, USA

6. Division of Cardiology, Department of Medicine, University of Pittsburgh School of Medicine, Pittsburgh, PA, USA

7. Division of Geriatric Medicine, Department of Medicine, University of Pittsburgh School of Medicine, Pittsburgh, PA, USA

8. Clinical Research Investigation and Systems Modeling of Acute Illness (CRISMA) Center, Department of Critical Care Medicine, University of Pittsburgh School of Medicine, Pittsburgh, PA, US

9. Department of Pathology, University of Pittsburgh School of Medicine, Pittsburgh, PA, USA 10. Health Services Division, UPMC, Pittsburgh, PA, USA 
medRxiv preprint doi: https://doi.org/10.1101/2021.09.03.21262551; this version posted September 9, 2021. The copyright holder for this preprint (which was not certified by peer review) is the author/funder, who has granted medRxiv a license to display the preprint in perpetuity.

11. Health System Office of Healthcare Innovation, UPMC, Pittsburgh, PA, USA

12. Division of Pulmonary, Allergy, and Critical Care Medicine, Department of Medicine, University of Pittsburgh School of Medicine, Pittsburgh, PA, USA

13. Department of Critical Care Medicine, University of Pittsburgh School of Medicine, Pittsburgh, PA, USA

14. Department of Medicine, University of Pittsburgh School of Medicine, Pittsburgh, PA, USA

15. Berry Consultants, Austin, TX, USA

\section{*CORRESPONDENCE}

David T. Huang, MD, MPH

Professor, Critical Care Medicine, Emergency Medicine, Clinical and Translational Science

UPMC and University of Pittsburgh

606B Scaife Hall

Pittsburgh, PA 15213

huangdt@upmc.edu 


\section{ABSTRACT}

3 Background: Neutralizing monoclonal antibodies (mAb) targeting SARS-CoV-2 decrease

4 hospitalization and death in patients with mild to moderate Covid-19. Yet, their clinical use is

5 limited, and comparative effectiveness is unknown.

7 Methods: We present the first results of an ongoing, learning health system adaptive platform

8 trial to expand $\mathrm{mAb}$ treatment to all eligible patients and evaluate the comparative effectiveness

9 of available mAbs. The trial launched March 10, 2021. Results are reported as of June 25, 2021

10 due to the U.S. federal decision to pause distribution of bamlanivimab-etesevimab; patient

11 follow-up concluded on July 23, 2021. Patients referred for mAb who met Emergency Use

12 Authorization criteria were provided a random $\mathrm{mAb}$ allocation of bamlanivimab, bamlanivimab-

13 etesevimab, or casirivimab-imdevimab with a therapeutic interchange policy. The primary

14 outcome was hospital-free days (days alive and free of hospital) within 28 days, where patients

15 who died were assigned -1 day. The primary analysis was a Bayesian cumulative logistic model

16 of all patients treated at an infusion center or emergency department, adjusting for treatment

17 location, age, sex, and time. Inferiority was defined as a 99\% posterior probability of an odds

18 ratio $<1$. Equivalence was defined as a $95 \%$ posterior probability that the odds ratio is within a

19 given bound.

21 Results: Prior to trial launch, 3.1\% (502) of 16,345 patients who were potentially eligible by an

22 automated electronic health record (EHR) screen received mAb. During the trial period, 23.2\%

$23(1,201)$ of 5,173 EHR-screen eligible patients were treated, a 7.5-fold increase. After including

24 additional referred patients from outside the health system, a total of 1,935 study patients 
25 received mAb therapy (128 bamlanivimab, 885 bamlanivimab-etesevimab, 922 casirivimab-

26 imdevimab). Mean age ranged from 55 to 57 years, half were female (range, 53\% to 54\%), and

$2717 \%$ were Black (range, $12 \%$ to $19 \%$ ). Median hospital-free days were 28 (IQR, 28 to 28 ) for

28 each mAb group. Hospitalization varied between groups (bamlanivimab, 12.5\%; bamlanivimab-

29 etesevimab, 14.7\%, casirivimab-imdevimab, 14.3\%). Relative to casirivimab-imdevimab, the

30 median adjusted odds ratios were 0.58 (95\% credible interval (CI), 0.30 to 1.16$)$ and $0.94(95 \%$

31 CI, 0.72 to 1.24 ) for the bamlanivimab and bamlanivimab-etesevimab groups, respectively.

32 These odds ratios yielded $91 \%$ and $94 \%$ probabilities of inferiority of bamlanivimab versus

33 bamlanivimab-etesevimab and casirivimab-imdevimab respectively, and an $86 \%$ probability of

34 equivalence between bamlanivimab-etesevimab and casirivimab-imdevimab, at the prespecified

35 odds ratio bound of 0.25 . Twenty-one infusion-related adverse events occurred in $0 \%(0 / 128)$,

$361.4 \%(12 / 885)$, and $1.0 \%$ (9/922) of patients treated with bamlanivimab, bamlanivimab-

37 etesevimab, and casirivimab-imdevimab, respectively.

39 Conclusion: In non-hospitalized patients with mild to moderate Covid-19, bamlanivimab,

40 compared to bamlanivimab-etesevimab and casirivimab-imdevimab, resulted in $91 \%$ and $94 \%$

41 probabilities of inferiority with regards to odds of improvement in hospital-free days within 28

42 days. There was an $86 \%$ probability of equivalence between bamlanivimab-etesevimab and

43 casirivimab-imdevimab at an odds ratio bound of 0.25 . However, the trial was unblinded early

44 due to federal distribution decisions, and no mAb met prespecified criteria for statistical

45 inferiority or equivalence. (ClinicalTrials.gov, NCT04790786). 


\section{INTRODUCTION}

47 Neutralizing monoclonal antibodies (mAb) targeting SARS-CoV-2 were granted U.S. Food and

48 Drug Administration (FDA) Emergency Use Authorization (EUA) for treatment of mild to

49 moderate Covid-19, and significantly decrease hospitalization and death in this patient

50 population. ${ }^{1-9}$ However, clinical use is limited due to lack of access, logistical challenges of

51 administration, and incomplete clinician and patient awareness. ${ }^{10}$ The comparative effectiveness

52 of one mAb versus another is also unknown. ${ }^{11}$

53

54 In February 2021, UPMC partnered with the U.S. Federal Covid-19 Response Team to expand

55 clinical use to all EUA-eligible patients and evaluate the comparative effectiveness of the

56 available mAbs using a learning health system approach. This approach embeds knowledge

57 generation into daily practice to seek continuous improvement in care. ${ }^{12,13}$ For all mAb-eligible

58 patients treated at UPMC, we set two objectives, (i.) to equitably treat as broad of a proportion of

59 mAb-eligible patients as possible, and (ii.) to compare effectiveness between mAbs overall and

60 over time as SARS-CoV-2 variants emerged. This report presents the first results of the

61 OPTIMISE-C19 (OPtimizing Treatment and Impact of Monoclonal antIbodieS through

62 Evaluation for Covid-19) trial. ${ }^{14}$

63

64 


\section{METHODS}

\section{Expansion of Monoclonal Antibody Access}

67 UPMC is an integrated network predominantly serving Western and Central Pennsylvania. Prior

68 to U.S. federal partnership, UPMC developed a mAb treatment infrastructure in response to the

69 bamlanivimab EUA issued November 9, 2020. ${ }^{7}$ The first patient was treated at a one of 18

70 outpatient infusion centers within this infrastructure on December 9, 2020. ${ }^{15.16}$ After U.S. federal

71 partnership, mAb infusion capacity was expanded to all emergency departments $(\mathrm{ED}, \mathrm{n}=31)$,

72 infusion center staffing and hours were increased, and a multifaceted outreach campaign to

73 patients and clinicians was launched. UPMC partnered with government public health bodies,

74 community outreach leaders, and neighboring health systems to increase awareness and referrals,

75 and a home infusion company to provide treatment for homebound patients (Chartwell

76 Pennsylvania, Oakdale, PA).

77

78 The UPMC Pharmacy and Therapeutics Committee developed a therapeutic interchange policy

79 on November 21, 2020 in response to the issuance of an EUA for casirivimab-imdevimab. ${ }^{9}$ The

80 policy considered all available mAb equivalent; a patient could receive any mAb based on local

81 inventory. The policy was updated to include bamlanivimab-etesevimab on February 9, 2021 and

82 to remove bamlanivimab on March 31, 2021 due to U.S. federal decisions. ${ }^{8,17}$ All pharmacies

83 supplying all infusion sites had equal opportunity to order any available mAb from a central

84 supply facility. All mAb were ordered by prescribers as a generic referral order and provided as

85 per FDA EUA guidance (Supplement). Prescribers were required to provide and review all mAb

86 EUA Fact Sheets with the patient at time of referral and explain the patient could receive any of

87 the EUA-governed mAb. ${ }^{7-9}$ 


\section{$89 \quad$ Trial Design and Oversight}

90 OPTIMISE-C19 is an open-label, pragmatic, comparative effectiveness, platform trial with

91 response-adaptive randomization. The three mAb (bamlanivimab, bamlanivimab-etesevimab,

92 and casirivimab-imdevimab) evaluated in this report were supplied by the U.S. federal

93 government. The trial was approved by the UPMC Quality Improvement Committee and

94 launched March 10, 2021 (Project ID 3280). The University of Pittsburgh Institutional Review

95 Board considered provision of mAb therapy quality improvement and only the additional data

96 collection and analyses represented research (STUDY21020179).

98 A custom application built into the electronic health record (EHR) linked local inventory to

99 patient encounters and provided a random mAb allocation at the time of referral, within the

100 therapeutic interchange policy. ${ }^{18}$ Allocation was initially assigned equally to available mAb.

101 Patients provided verbal consent to receive mAb therapy as part of routine care. The prescriber

102 and/or patient could request a specific mAb if desired.

103

104 Patients

105 A centralized monoclonal antibody operations team confirmed patient eligibility upon referral.

106 Patients were eligible for mAb if they met EUA criteria, which included patients with a positive

107 SARS-CoV-2 polymerase chain reaction or antigen test, mild to moderate symptoms for 10 days

108 or less, and risk factor(s) for progression to severe Covid-19. The EUA criteria excluded patients

109 who required supplemental oxygen above baseline requirements, weighed $<40 \mathrm{~kg}$, were $<12$ 
110 years of age, or were hospitalized for Covid-19 (Supplement). Patients were screened in the ED

111 or outpatient infusion centers.

\section{Outcomes}

114 To evaluate clinical mAb use expansion, we screened for potential eligibility based on EHR

115 identification of all outpatients with a positive SARS-CoV-2 polymerase chain reaction or 116 antigen test performed within the health system and an EUA-defined risk factor for progression

117 to severe disease. Race was derived from registration system data using fixed categories

118 consistent with the Centers for Medicare \& Medicaid Services EHR meaningful use dataset and

119 the AMA Manual of Style. ${ }^{19,20}$ Pre-specified categories included non-Hispanic Black, non-

120 Hispanic White, and Other. Individuals were considered Other due to small sample sizes for

121 Hispanic, American Indian, and other races and ethnicities. Geographic distribution of mAb

122 treatment was illustrated using zip code of patient residence. ${ }^{21,22}$

124 To evaluate comparative effectiveness, the primary outcome was hospital-free days up to day 28

125 after $\mathrm{mAb}$ treatment. This outcome is an ordinal endpoint with death up to day 28 as the worst

126 outcome (labeled -1), then the length of time alive and free of hospital, such that the best

127 outcome would be 28 hospital-free days. If a patient had intervening days free of hospital and

128 was then re-hospitalized, the patient was given credit for the intervening days as free of the

129 hospital. Secondary outcomes included mortality at 28 days. We evaluated rates of

130 hospitalization by infusion location, and incidence of adverse events (Supplement). We assessed

131 SARS-CoV-2 variant prevalence in our Pennsylvania catchment over time using Global

132 Initiative on Sharing All Influenza Data (GISAID) data. ${ }^{23}$ 


\section{Data Collection}

135 OPTIMISE-C19 was embedded in the EHR to access routine patient care data and was

136 augmented by manual review and data collection. We ascertained the primary outcome of

137 hospital-free days by linking inpatient (Cerner, Kansas City, Missouri) and outpatient (Epic,

138 Madison, Wisconsin) EHRs, as shown in prior work. ${ }^{18}$ We conducted patient-directed phone

139 calls at day 28 to ascertain health care encounters outside our health system, and Social Security

140 Administration Death Master File queries for vital status. ${ }^{24}$ We collected adverse events in i.) a

141 secure, electronic file sharing application completed by infusion center nurses on the day of mAb

142 treatment, and ii.) an internal patient safety reporting system for adverse reactions completed by

143 nursing and physician staff in infusion centers and EDs. Adverse event severity was adjudicated

144 blinded to mAb type.

\section{Statistical Analysis}

147 To determine the epidemiology and equitability of mAb infusions in our region, we measured the

148 proportion of EHR-screen eligible patients treated with any mAb stratified by demographics,

149 geography, and prior to or after trial launch. Treatment "prior to the trial" was from December 9,

1502020 until March 9, 2021, and “during the trial” from March 10 to June 25, 2021.

152 To analyze comparative effectiveness, the trial statistical analysis plan was written by blinded

153 investigators prior to data lock and analysis (Supplement) and applied to patients treated with

$154 \mathrm{mAb}$ from March 10, 2021 to June 25, 2021. The platform is designed to continuously evaluate 155 multiple mAb, with randomization continuing until pre-determined statistical thresholds are met. 
156 The trial launched with equal allocation randomization and planned interim analyses for adaptive

157 randomization where mAb performing better would be given higher randomization probabilities.

158 The mAb arm at the first adaptive analysis with the largest sample size was specified as the

159 referent arm, as there was no non-mAb control and all patients received active treatment. All

$160 \mathrm{mAb}$ were compared to each other. The methods and results are reported in accordance with the

161 CONSORT Pragmatic Extension checklist (Supplement). ${ }^{25}$ An unblinded statistical analysis

162 committee conducted interim and final analyses with $\mathrm{R}$ version 4.0.5 using the RStan package

163 version 2.21.0 (R Foundation, Vienna, Austria) and reported results to the UPMC Chief Medical

164 Officer who functioned in a data and safety monitor role for the study.

166 The primary analysis population was the "as-infused" population which consisted of patients

167 randomly allocated $\mathrm{mAb}$ and subsequently treated. As all trial arms included mAb, there was no

168 anticipated relationship between lack of infusion and the assigned arm. Baseline patient

169 characteristics of those infused were compared to those allocated but not infused using mean

170 (SD) or median (IQR) for continuous variables, and proportions for categorical variables.

171

172 The primary analysis model was a Bayesian cumulative logistic model that adjusted for

173 treatment location (infusion center or ED), age $(<30,30-39,40-49,50-59,60-69,70-79$, and $\geq 80$

174 years), sex, and time (2-week epochs). The comparison between individual mAbs were based on

175 the relative odds ratio between a given two arms for the ordinal primary outcome. An odds ratio

176 for an arm to a comparator greater than 1 implies improved outcomes on the ordinal scale. A

177 sliding scale of equivalence was set according to odds ratio bounds of $0.25,0.20,0.15,0.10$, and

178 0.05. Equivalence between two arms was defined as a 95\% posterior probability that the odds 
179 ratio is within a given odds ratio bound. Inferiority of one arm compared to another was defined as a $99 \%$ posterior probability of an odds ratio less than 1.

182 To determine potential differential treatment effects of mAbs by Covid-19 variant type, patients

183 were categorized into four time epochs relative to variant prevalence in 2021 (March 10 - 31;

184 April 1 - April 30; May 1 - 31; June 1-25). Treatment effects were measured from the primary model over time with hierarchical prior distributions.

Decision to publish interim results

188 The U.S. Department of Health and Human Services halted distribution of bamlanivimab alone 189 on March 25, 2021, and of bamlanivimab-etesevimab on June 25, 2021, due to concern of lack of 190 efficacy against certain SARS-CoV-2 variants that were predominant in the U.S. at those

191 times. ${ }^{26,27}$ As further treatment with these mAbs was not possible, we unblinded and analyzed 192 patients allocated through June 25, 2021, with follow up completed by July 23, 2021.

\section{RESULTS}

\section{Expansion of monoclonal antibody treatment}

196 Prior to the trial, 16,345 patients were EHR-screen eligible. Of these, 502 patients overall (3.1\%)

197 were treated with mAb, of whom the proportion of Black $(2.6 \%)$ and White $(3.1 \%)$ treated

198 patients were similar. After trial launch, 1,201 of 5,173 EHR-screen eligible patients (23.2\%)

199 were treated. The proportion of eligible White patients receiving mAb increased from 3.1 to

$20021.6 \%$ and eligible Black patients receiving mAb increased from 2.6 to $29.9 \%$ during the trial.

201 Broad geographic expansion was evident across the catchment (Figure 1). 
203 Trial patients

204 Between March 10 and June 25, 2021, 5,173 outpatients with a positive SARS-CoV-2 test within

205 UPMC were EHR-screen eligible, of whom 1,382 were referred and underwent random mAb

206 allocation. 1,084 EUA-eligible patients with a positive SARS-CoV-2 test from outside of UPMC

207 were also referred, yielding a total of 2,466 patients who were assigned a random $\mathrm{mAb}$

208 allocation. Of these, 1,935 (78\%) were infused and comprised the primary analysis cohort

209 (bamlanivimab $[\mathrm{n}=128]$, bamlanivimab-etesevimab $[\mathrm{n}=885]$, casirivimab-imdevimab $[\mathrm{n}=$

210 922], Figure 2). Of the 531 patients assigned a random mAb allocation and excluded from the

211 primary analysis, most $(n=300,56 \%)$ were not infused due to becoming clinically ineligible at

212 time of infusion scheduling $(\mathrm{n}=154,29 \%)$ or patient declining treatment $(\mathrm{n}=146,27 \%)$.

213 Eighty-eight patients (17\%) received mAb at a location without available EHR data or while

214 hospitalized for non-Covid-19 reasons. No patient or provider requested a specific mAb different 215 than randomized assignment.

217 Baseline characteristics were similar across groups (Table 1). The mean age for the three groups

218 was 55 - 57 years, half were female (range, 53\% - 54\%), 18\% were Black (range 12\% - 19\%),

219 and the most common risk factors were advanced age, high body mass index, and hypertension.

220 Of the 241 patients for whom vaccine status was known, 57 (24\%) reported being unvaccinated,

$221120(49 \%)$ partly vaccinated, and 64 (27\%) fully vaccinated. Mean duration of symptom onset to

222 referral was 5 (2.1) days. 


\section{Primary outcome}

226 The median hospital-free days were 28 (IQR, 28-28) for each mAb group (Table 2, Figure 3).

227 Relative to the casirivimab-imdevimab group, the posterior median adjusted odds ratios from the

228 primary model were 0.58 (95\% credible interval, 0.30 to 1.16$)$ and 0.94 (95\% credible interval,

2290.72 to 1.24 ) for the bamlanivimab and bamlanivimab-etesevimab groups, respectively. The

230 probabilities of inferiority for bamlanivimab versus bamlanivimab-etesevimab and casirivimab-

231 imdevimab were $91 \%$ and $94 \%$ respectively. The probability of equivalence between

232 bamlanivimab-etesevimab and casirivimab-imdevimab with a bound of 0.25 for the odds ratio

233 was $86 \%$. No comparison met prespecified criteria for statistical inferiority or equivalence.

\section{Secondary outcomes}

236 The 28-day mortality rates were $0.8 \%(1 / 128), 0.8 \%$ (7/885), and $0.7 \%(6 / 922)$ and

237 hospitalization rates were $12.5 \%(16 / 128), 14.7 \%(130 / 885)$, and $14.3 \%(132 / 922)$, in the

238 bamlanivimab, bamlanivimab-etesevimab, and casirivimab-imdevimab groups, respectively

239 (Table 2). For patients receiving $\mathrm{mAb}$ in an outpatient infusion center, rates of hospitalization

240 after treatment were 7.8\% (bamlanivimab), 6.5\% (bamlanivimab-etesevimab), and 6.9\%

241 (casirivimab-imdevimab). For patients receiving $\mathrm{mAb}$ in an $\mathrm{ED}$, rates of hospitalization after

242 treatment were 32\% (bamlanivimab), 23.7\% (bamlanivimab-etesevimab), and 21.7\%

243 (casirivimab-imdevimab).

245 Adverse events

246 Twenty-one infusion-related adverse events occurred in $0 \%(0 / 128), 1.4 \%(12 / 885)$, and $1.0 \%$

247 (9/922) of patients treated with bamlanivimab, bamlanivimab-etesevimab, and casirivimab- 
248 imdevimab, respectively. Five events (0 bamlanivimab, 1 bamlanivimab-etesevimab, 4

249 casirivimab-imdevimab) were adjudicated as serious (Supplement).

\section{Differences in treatment over time}

252 During the trial the Alpha SARS-CoV-2 variant was the dominant variant of concern, while the

253 Delta variant became more prevalent in the final time epoch (Supplement). We found no

254 relative difference in mAb treatment effects over time and no comparisons reached a pre-

255 specified statistical threshold (Supplement).

\section{DISCUSSION}

258 In a learning healthcare system trial of mAb for Covid-19, treatment of EHR-screen eligible

259 patients increased 7.5-fold, particularly among historically and geographically underserved

260 populations. We found a $91 \%$ and $94 \%$ probability of inferiority of bamlanivimab respectively to

261 bamlanivimab-etesevimab and casirivimab-imdevimab, and an $86 \%$ probability of equivalence

262 between bamlanivimab-etesevimab and casirivimab-imdevimab at the first pre-specified bound,

263 with regard to the odds of improvement in hospital-free days by 28 days. However, the

264 bamlanivimab and bamlanivimab-etesevimab arms were stopped early, and the identified

265 probabilities did not meet prespecified statistical triggers for trial conclusions of inferiority or

266 equivalence.

268 OPTIMISE-C19 is designed to continuously compare all available mAb for Covid-19 and can

269 stop mAb arms based on internal statistical triggers or external factors, such as U.S. federal

270 decisions limiting mAb availability or re-introduction of mAb into distribution networks. Had 
271 federal decisions not prompted unblinding, the internal action would have been to generate

272 updated randomization proportions and continue enrollment. The trial is currently evaluating

273 casirivimab-imdevimab and sotrovimab. ${ }^{28,29}$

274

275 Systematic inequities have exacerbated racial health disparities throughout the Covid-19

276 pandemic, and a focused effort on equitable, expanded access to life-saving treatments is crucial

277 for population health. ${ }^{30}$ This trial was able to increase access using a multifaceted approach: 1)

278 infrastructure with infusion locations in all geographic regions, 2) comprehensive, electronic

279 screening of all patients within the system with a positive SARS-CoV-2 followed by direct-to-

280 patient outreach phone calls, 3) paper referral form for patients without access to an in-system

281 provider, 4) community leader and existing outreach network collaboration for patient

282 engagement, 5) phone line for patients and community members to call and speak with a

283 healthcare professional, 6) providing infusions at home for patients without transportation.

285 The finding of potential inferiority of bamlanivimab is similar to mechanistic studies that suggest

286 a waning efficacy of bamlanivimab in the face of certain SARS-CoV-2 variants. It supports the

287 FDA decision to revoke the bamlanivimab EUA. ${ }^{26}$ A recent observational study reached a

288 different conclusion and found similar effectiveness between bamlanivimab and casirivimab-

289 imdevimab. ${ }^{31}$ However, this study analyzed patients treated between November 2020 and

290 February 2021, prior to widespread emergence of variants and U.S. federal decisions to halt 291 bamlanivimab distribution. 
293 SARS-CoV-2 variant epidemiology changes rapidly and this report addresses a period when the

294 Alpha variant was dominant, and the Delta variant was not widespread. Notably, the U.S. federal

295 government reinstated circulation of bamlanivimab-etesevimab on August 27, 2021 in areas

296 where variant resistance to this $\mathrm{mAb}$ is $\leq 5 \%$, based on in vitro data of activity against the Delta

297 variant, and lack of activity against the Beta, Gamma, Delta plus, and B.1.621 variants. ${ }^{31,32}$ The

298 similar effectiveness of bamlanivimab-etesevimab and casirivimab-imdevimab in the current

299 trial supports this decision. Also aligning with these data is a recent observational study of 165

300 patients that found no difference in hospitalization or death between bamlanivimab-etesevimab

301 and casirivimab-imdevimab in patients infected with Alpha, but worse outcomes with

302 bamlanivimab-etesevimab in patients infected with Gamma. ${ }^{33}$

304 The strengths of this report include capture of nearly all patients infused with mAb from 49 sites

305 across a large geographic region, enhancing the generalizability of the results. In addition, an

306 advantage of the Bayesian design is that any data, including data following unplanned cessation

307 in enrollment into a trial arm, can be analyzed and quantified as posterior probabilities, which is

308 potentially more useful and is more quantitative than a frequentist conclusion of failure to reject

309 a null hypothesis possibly because of lack of power. ${ }^{34}$ Third, the trial was embedded into usual

310 care which enhanced patient and provider engagement. ${ }^{12}$ The trial also has limitations. First, the

311 results are presented before any prespecified internal trigger was reached. Nonetheless, to our

312 knowledge, this trial represents the largest randomized comparative effectiveness data of $\mathrm{mAb}$

313 for Covid-19. Second, the absence of patient-level variant data limited ability to directly assess

314 comparative effectiveness relative to variant strains. Alpha was also the dominant variant during

315 the majority of the trial. Using regional data as a surrogate for variant data in the Pennsylvania 
316 population over time, we found no difference in treatment effect over time. Third, we primarily

317 relied on UPMC EHR data to capture death and hospitalization, and patients may have accessed

318 care outside our health system after mAb treatment. We conducted direct-to patient calls and

319 national death registry queries to address this concern. Fourth, the EHR eligibility screen

320 identified most, but not all EUA risk factors, and could not identify if a patient was symptomatic.

\section{Conclusion}

323 In non-hospitalized patients with mild to moderate Covid-19, bamlanivimab, compared to

324 bamlanivimab-etesevimab and casirivimab-imdevimab, resulted in $91 \%$ and $94 \%$ probabilities of

325 inferiority with regards to odds of improvement in hospital-free days within 28 days. There was

326 an $86 \%$ probability of equivalence between bamlanivimab-etesevimab and casirivimab-

327 imdevimab at an odds ratio bound of 0.25 . However, the trial was unblinded early to these mAb

328 due to federal distribution decisions, and no mAb met prespecified criteria for statistical

329 inferiority or equivalence. 
331 Acknowledgements: The authors thank the clinical staff of the UPMC monoclonal antibody

332 infusion centers as well as the support and administrative staff behind this effort, including but

333 not limited to: Michelle Adam, Jodi Ayers, Ashley Beyerl, Trudy Bloomquist, Mikaela Bortot,

334 Jonya Brooks, Sherry Casali, Jeana Colella, Jennifer Dueweke, Jesse Duff, Janice Dunsavage,

335 Jessica Fesz, Kathleen Flinn, Daniel Gessel, Amy Helmuth, Erik Hernandez, Larry Hruska,

336 Allison Hydzik, Le Ann Kaltenbaugh, LuAnn King, Jim Krosse, Sheila Kruman, Amy Lukanski,

337 Hilary Maskiewicz, Debra Masser, Katelyn Mayak, Rebecca Medva, Theresa Murillo, Melanie

338 Pierce, Teressa Polcha, Kevin Pruznak, Debra Rogers, Rozalyn Russell, Sarah Sakaluk, Heather

339 Schaeffer, Robert Shulik, Libby Shumaker, Susan Spencer, Betsy Tedesco, Ken Trimmer,

340 Jennifer Zabala, and their entire teams. Donald M. Yealy, MD provided data and safety

341 monitoring for the trial.

342

343 Funding Statement: This work received no external funding. The U.S. federal government

344 provided the monoclonal antibody treatments reported in this manuscript.

346 Conflict of Interest Disclosure: None of the authors received any payments or influence from a

347 third-party source for the work presented. 


\section{REFERENCES}

349 1. Jiang S, Hillyer C, Du L. Neutralizing antibodies against SARS-CoV-2 and other human coronaviruses. Trends Immunol. 2020 May;41(5):355-359. doi:10.1016/j.it.2020.03.007.

2. Bariola JR, McCreary EK, Wadas RJ, et al. Impact of bamlanivimab monoclonal antibody 352 treatment on hospitalization and mortality among non-hospitalized adults with severe acute 353 respiratory syndrome coronavirus 2 infection. Open Forum Infect Dis. 2021 May 17;8(7):ofab254. doi: 10.1093/ofid/ofab254.

3. Chen P, Nirula A, Heller B, et al. SARS-CoV-2 neutralizing antibody LY-CoV555 in outpatients with Covid-19. N Engl J Med. 2021 Jan 21;384(3):229-237. doi: 10.1056/NEJMoa2029849.

4. Dougan M, Nirula A, Azizad M, et al. Bamlanivimab plus etesevimab in mild or moderate Covid-19. N Engl J Med. 2021 Jul. doi:10.1056/nejmoa2102685.

5. Weinreich D, Sivapalasingam S, Norton T, et al. REGEN-COV antibody cocktail clinical outcomes study in COVID-19 outpatients. medRxiv. 2021 June 6. doi: 10.1101/2021.05.19.21257469.

6. U.S. Food and Drug Administration News Release. Coronavirus (COVID-19) update: FDA authorizes monoclonal antibody for treatment of COVID-19. 2020 November 9. Available at:

365 https://bit.ly/2HesBBs. Accessed July 20, 2021.

366 7. U.S. Food and Drug Administration. Fact sheet for health care providers emergency use 367 authorization (EUA) of bamlanivimab. Available at: https://www.fda.gov/media/143603/download. Accessed July 20, 2021. 
8. U.S. Food and Drug Administration. Fact sheet for health care providers emergency use authorization (EUA) of bamlanivimab and etesevimab. Available at: https://www.fda.gov/media/145802/download. Accessed July 20, 2021.

372 9. U.S. Food and Drug Administration. Fact sheet for health care providers emergency use 373 authorization (EUA) of REGEN-COVTM. Available at:

374 https://www.regeneron.com/downloads/treatment-covid19-eua-fact-sheet-for-hcp.pdf. $375 \quad$ Accessed July 20, 2021.

376 10. Bernstein L, McGinley L. Monoclonal antibodies are free and effective against covid-19, but 377 few people are getting them. The Washington Post. Published 20 Aug 2021. Accessed 28 Aug 2021. Available from: https://www.washingtonpost.com/health/covid-monoclonalallocate scarce COVID-19 monoclonal antibody treatments to eligible patients examined in new rapid response to government. 2021 January 29. Available at: https://www.nationalacademies.org/news/2021/01/strategies-to-allocate-scarce-Covid-19monoclonal-antibody-treatments-to-eligible-patients-examined-in-new-rapid-response-to-

386 12. Angus DC. Optimizing the Trade-off Between Learning and Doing in a Pandemic. JAMA 2020;323(19):1895-1896. DOI: 10.1001/jama.2020.4984. 
14. Huang DT, McCreary EK, Bariola JR, et al. The UPMC OPTIMISE-C19 (OPtimizing Treatment and Impact of Monoclonal antIbodieS through Evaluation for COVID-19) trial: a structured summary of a study protocol for an open-label, pragmatic, comparative effectiveness platform trial with response-adaptive randomization. Trials. 2021 May 25;22(1):363. doi: 10.1186/s13063-021-05316-3.

15. Angus D. Fusing randomized trials with big data: the key to self-learning health care systems? JAMA 2015;314:767-8. doi: 10.1001/jama.2015.7762.

16. Bariola JR, McCreary EK, Khadem T, et al. Establishing a distribution network for COVID19 monoclonal antibody therapy across a large health system during a global pandemic. Open Forum Infect Dis. 2021 Mar 26;8(7):ofab151. doi: 10.1093/ofid/ofab151.

401 17. U.S. Department of Health \& Human Services Public Health Emergency. Coronavirus (COVID-19) Update: FDA revokes emergency use authorization for monoclonal antibody bamlanivimab. 2021 April 16. Available at: https://www.fda.gov/news-events/pressannouncements/coronavirus-Covid-19-update-fda-revokes-emergency-use-authorizationmonoclonal-antibody-bamlanivimab. Accessed on July 20, 2021.

406 18. Reitz KM, Seymour CW, Vates J, et al. Strategies to Promote ResiliencY (SPRY): a 407 randomised embedded multifactorial adaptative platform (REMAP) clinical trial protocol to 408 study interventions to improve recovery after surgery in high-risk patients. BMJ Open. 2020 409 Sep 29;10(9):e037690. doi: 10.1136/bmjopen-2020-037690.

410 19. Centers for Medicare and Medicaid Services. Meaningful use data; public use files - CMS.

411 Available at: www.cms.gov. Accessed September 3, 2021. 
20. Christainsen SL, Cintron MY, Desai A, et al. American Medical Association Manual of Style, $11^{\text {th }}$ edition, a guide for authors and editors. Oxford University Press 2020. Available at: www.amamanualofstyle.com. Accessed September 3, 2021.

415 21. Kind AJH, Buckingham W. Making neighborhood disadvantage metrics accessible: the 416 neighborhood atlas. N Engl J Med. 2018. 378: 2456-2458. doi: 10.1056/NEJMp1802313.

417 22. University of Wisconsin School of Medicine Public Health. 2015 Area Deprivation Index 418 v2.0. Downloaded from https://www.neighborhoodatlas.medicine.wisc.edu/ August 1, 2021.

419 23. Global Initiative on Sharing Avian Influenza Data. Tracking of variants. Available at 420 https://www.gisaid.org/. Accessed on July 20, 2021.

421 24. Social Security Administration. Social Security Master File of Social Security Number

422 Holders and Applications: Death Information. Available at:

423 https://www.ssa.gov/dataexchange/request_dmf.html. Accessed August 1, 2021.

424 25. Zwarenstein M, Treweek S, Gagnier JJ, et al. Improving the reporting of pragmatic trials: an 425 extension of the CONSORT statement. BMJ. 2008 Nov 11;337:a2390. doi:

$426 \quad$ 10.1136/bmj.a2390.

427 26. U.S. Department of Health \& Human Services Public Health Emergency. Coronavirus

428 (COVID-19) Update: FDA revokes emergency use authorization for monoclonal antibody

429 bamlanivimab. 2021 April 16. Available at: https://www.fda.gov/news-events/press-

430 announcements/coronavirus-Covid-19-update-fda-revokes-emergency-use-authorization-

431 monoclonal-antibody-bamlanivimab. Accessed on July 20, 2021.

432 27. U.S. Department of Health \& Human Services Public Health Emergency. Pause in the 433 distribution of bamlanivimab/etesevimab. 2021 June 25. Available at:

434 https://www.phe.gov/emergency/events/COVID19/investigation-MCM/BamlanivimAb- 
etesevimAb/Pages/bamlanivimAb-etesevimAb-distribution-pause.aspx. Accessed on July 20, 2021.

28. U.S. Department of Health \& Human Services. Federal response to COVID-19: monoclonal antibody update. 2021 July 30. Available at: https://www.phe.gov/emergency/events/COVID19/investigation-MCM/Documents/USG-

$440 \quad$ COVID19-Tx-Playbook.pdf. Accessed August 1, 2021.

441 29. Food and Drug Administration. Fact sheet for healthcare providers: emergency use

442 authorization (EUA) of sotrovimab. 2021. Available at: https://www.fda.gov/media/149534/download. Accessed on July 20, 2021.

444 30. Ganesh R, Philpot LM, Bierle DM, et al. Real-world clinical outcomes of bamlanivimab and 445 casirivimab-imdevimab among high-risk patients with mild to moderate coronavirus disease 2019. J Infect Dis. 2021 Jul 19:jiab377. doi: 10.1093/infdis/jiab377.

447 31. Falcone M, Tiseo G, Valoriani B, et al. Efficacy of Bamlanivimab/Etesevimab and 448 Casirivimab/Imdevimab in Preventing Progression to Severe COVID-19 and Role of 449 Variants of Concern [published online ahead of print, 2021 Aug 25]. Infect Dis Ther. 2021;1450 10. doi:10.1007/s40121-021-00525-4

451 32. Connor BA, Couto-Rodriguez M, Barrows JE, et al. Monoclonal antibody therapy in a 452 vaccine breakthrough SARS-CoV-2 hospitalized Delta (B.1.617.2) variant case. Int J Infect 453 Dis. 2021 Jul 13;110:232-234. doi: 10.1016/j.ijid.2021.07.029.

454 33. Planas D, Veyer D, Baidaliuk A. Reduced sensitivity of infectious SARS-CoV-2 variant 455 B.1.617.2 to monoclonal antibodies and sera from convalescent and vaccinated individuals. 456 bioRxiv. 2021 May 27. doi: 10.1101/2021.05.26.445838. 
medRxiv preprint doi: https://doi.org/10.1101/2021.09.03.21262551; this version posted September 9, 2021. The copyright holder for this preprint

(which was not certified by peer review) is the author/funder, who has granted medRxiv a license to display the preprint in perpetuity.

All rights reserved. No reuse allowed without permission.

457 34. Quintana M, Viele K, Lewis RJ. Bayesian Analysis: Using Prior Information to Interpret the

458 Results of Clinical Trials. JAMA. 2017;318(16):1605-1606. doi:10.1001/jama.2017.15574

459 
Table 1. Demographic and Clinical Characteristics of the Patients at Baseline and

\section{Comparison by Monoclonal Antibody Group.}

\begin{tabular}{|c|c|c|c|c|}
\hline Characteristic & $\begin{array}{c}\text { Bamlanivimab } \\
(\mathrm{n}=128)\end{array}$ & $\begin{array}{c}\text { Bamlanivimab } \\
\text { - etesevimab } \\
(\mathrm{n}=885)\end{array}$ & $\begin{array}{c}\text { Casirivimab } \\
\text {-imdevimab } \\
(\mathrm{n}=922) \\
\end{array}$ & $\begin{array}{c}\text { Entire } \\
\text { Cohort } \\
(\mathrm{n}=1,935) \\
\end{array}$ \\
\hline Age, mean (SD) & $57(17)$ & $56(16)$ & $55(16)$ & $56(16)$ \\
\hline Female sex, n (\%) & $69(54 \%)$ & $470(53 \%)$ & $502(54 \%)$ & $1,041(54 \%)$ \\
\hline \multicolumn{5}{|l|}{ Race, n $(\%) \ddagger$} \\
\hline White & $104(81 \%)$ & $693(78 \%)$ & $701(76 \%)$ & $1,498(77 \%)$ \\
\hline Black & $15(12 \%)$ & $148(17 \%)$ & $173(19 \%)$ & $336(17 \%)$ \\
\hline Other & $1(0.8 \%)$ & $23(2.6 \%)$ & $27(2.9 \%)$ & $51(2.6 \%)$ \\
\hline Unknown & $8(6.3 \%)$ & $21(2.4 \%)$ & $21(2.3 \%)$ & $50(2.6 \%)$ \\
\hline \multicolumn{5}{|l|}{ Vaccine status } \\
\hline Fully vaccinated & $2(1.6 \%)$ & $43(4.9 \%)$ & $19(2.1 \%)$ & $64(3.3 \%)$ \\
\hline Partially vaccinated & $26(20 \%)$ & $39(4.4 \%)$ & $55(6.0 \%)$ & $120(6.2 \%)$ \\
\hline Unvaccinated & $0(0 \%)$ & $27(3.1 \%)$ & $30(3.3 \%)$ & $57(2.9 \%)$ \\
\hline Unknown & $100(78 \%)$ & $776(88 \%)$ & $818(89 \%)$ & $1,694(88 \%)$ \\
\hline Body mass index, mean (SD) & $35.6(9.1)$ & $34.5(8.4)$ & $35.1(8.4)$ & $34.8(8.4)$ \\
\hline Days from randomization to infusion, mean (SD) & $0.6(0.9)$ & $0.4(0.7)$ & $0.4(0.8)$ & $0.4(0.8)$ \\
\hline Days from symptoms to randomization, mean (SD) & $5.0(2.0$ & $5.4(2.0)$ & $4.9(2.0)$ & $5.0(2.1)$ \\
\hline Days from symptoms to infusion, mean (SD) & $6.3(1.8)$ & $6.0(1.9)$ & $6.2(2.0)$ & $6.1(1.9)$ \\
\hline \multicolumn{5}{|l|}{ Location } \\
\hline Infusion center & $103(81 \%)$ & $463(52 \%)$ & $462(50 \%)$ & $1,028(53 \%)$ \\
\hline Emergency department & $25(20 \%)$ & $422(48 \%)$ & $460(50 \%)$ & $907(47 \%)$ \\
\hline \multicolumn{5}{|l|}{ Qualifying EUA criteria } \\
\hline March 10, 2021 - May 23, 2021 & $128(100 \%)$ & $753(85 \%)$ & $783(85 \%)$ & $1,664(86 \%)$ \\
\hline Age $\geq 65$ years & $39(31 \%)$ & $223(30 \%)$ & $236(30 \%)$ & $498(30 \%)$ \\
\hline Body mass index $\geq 35$ & $33(47 \%)$ & $238(47 \%)$ & $257(49 \%)$ & $528(48 \%)$ \\
\hline Chronic kidney disease & $4(4.0 \%)$ & $43(7.7 \%)$ & $51(8.8 \%)$ & $98(7.9 \%)$ \\
\hline Diabetes & $24(24 \%)$ & $154(28 \%)$ & $154(27 \%)$ & $332(27 \%)$ \\
\hline Immunosuppressive disease or treatment $\S$ & $26(26 \%)$ & $158(28 \%)$ & $155(27 \%)$ & $339(27 \%)$ \\
\hline Sickle cell disease & $0(0 \%)$ & $0(0 \%)$ & $0(0 \%)$ & $0(0 \%)$ \\
\hline \multicolumn{5}{|l|}{ Age $\geq 55$ years and } \\
\hline Cardiovascular disease & $29(26 \%)$ & $112(17 \%)$ & $117(17 \%)$ & $258(18 \%)$ \\
\hline Hypertension & $43(39 \%)$ & $224(35 \%)$ & $223(33 \%)$ & $490(34 \%)$ \\
\hline Respiratory condition & $29(26 \%)$ & $124(19 \%)$ & $119(18 \%)$ & $272(19 \%)$ \\
\hline Age $12-17$ years with qualifying criterion & $1(0.8 \%)$ & $13(1.7 \%)$ & $6(0.8 \%)$ & $20(1.2 \%)$ \\
\hline May 24, 2021 - June 25, 2021 II & $0(0 \%)$ & $132(15 \%)$ & $139(15 \%)$ & $271(14 \%)$ \\
\hline Age $\geq 65$ years & - & $30(23 \%)$ & $37(27 \%)$ & $67(25 \%)$ \\
\hline Body mass index $>25$ & - & $88(89 \%)$ & $90(90 \%)$ & $178(89 \%)$ \\
\hline Chronic kidney disease & - & $7(6.6 \%)$ & $7(6.5 \%)$ & $14(6.5 \%)$ \\
\hline Diabetes & - & $29(27 \%)$ & $25(23 \%)$ & $54(25 \%)$ \\
\hline Down syndrome & - & $0(0 \%)$ & $0(0 \%)$ & $0(0 \%)$ \\
\hline Current or former smoker & - & $25(31 \%)$ & $32(37 \%)$ & $57(34 \%)$ \\
\hline Current or history of substance abuse & - & $0(0 \%)$ & $2(2.3 \%)$ & $2(1.2 \%)$ \\
\hline Immunosuppressive disease or treatment & - & $29(27 \%)$ & $27(25 \%)$ & $56(26 \%)$ \\
\hline Sickle cell disease & - & $0(0 \%)$ & $0(0 \%)$ & $0(0 \%)$ \\
\hline Cardiovascular disease & - & $24(23 \%)$ & $14(13 \%)$ & $38(18 \%)$ \\
\hline Hypertension & - & $61(58 \%)$ & $52(48 \%)$ & $113(53 \%)$ \\
\hline Respiratory condition & - & $42(40 \%)$ & $40(37 \%)$ & $82(38 \%)$ \\
\hline
\end{tabular}


medRxiv preprint doi: https://doi.org/10.1101/2021.09.03.21262551; this version posted September 9, 2021. The copyright holder for this preprint

(which was not certified by peer review) is the author/funder, who has granted medRxiv a license to display the preprint in perpetuity.

All rights reserved. No reuse allowed without permission.

$1(0.8 \%)$

$2(1.4 \%)$

$3(1.1 \%)$

$467 \dagger \quad$ Percentages shown correspond to those patients within each time period. Race was

468 reported by the patients.

$469+\quad$ Race was reported by the patients.

$470 \S$ Immunosuppressive disease or treatment was defined as a history of HIV, cancer,

471 transplant (solid organ, stem cell, bone marrow), chemotherapy treatment, lupus,

$472 \quad$ rheumatoid arthritis, or liver disease.

473 II EUA criteria were expanded May 14, 2021, and operationalized at UPMC May 24, 2021.

474

475

476

477

478 
medRxiv preprint doi: https://doi.org/10.1101/2021.09.03.21262551; this version posted September 9, 2021. The copyright holder for this preprint (which was not certified by peer review) is the author/funder, who has granted medRxiv a license to display the preprint in perpetuity.

479 Table 2. Primary Outcomes and Analysis.

\begin{tabular}{|c|c|c|c|}
\hline Outcome/analysis & $\begin{array}{l}\text { Bamlanivimab } \\
\quad(\mathrm{n}=128)\end{array}$ & $\begin{array}{l}\text { Bamlanivimab } \\
\text {-etesevimab } \\
(\mathrm{n}=885)\end{array}$ & $\begin{array}{c}\text { Casirivimab } \\
\text {-imdevimab } \\
(\mathrm{n}=922)\end{array}$ \\
\hline \multicolumn{4}{|l|}{ Primary outcome, hospital-free days, median } \\
\hline $\begin{array}{l}\text { (IQR) } \\
\text { Patients with } 28 \text { hospital-free days, n (\%) }\end{array}$ & $112(87.5 \%)$ & $755(85.3 \%)$ & $790(85.7 \%)$ \\
\hline \multicolumn{4}{|l|}{ Subcomponents of hospital-free days } \\
\hline Deaths, n (\%) & $1(0.8 \%)$ & $7(0.8 \%)$ & $6(0.7 \%)$ \\
\hline $\begin{array}{l}\text { Hospital length of stay among hospitalized } \\
\text { patients, median days (IQR) }\end{array}$ & Hospital length of stay among hospitalized & $4(3-7)$ & $3(2-6)$ \\
\hline Hospitalized, n (\%) & $16(12.5 \%)$ & $130(14.7 \%)$ & $132(14.3 \%)$ \\
\hline $\begin{array}{l}\text { After mAb infusion in emergency } \\
\text { department } \\
\text { After mAb infusion in infusion center }\end{array}$ & $\begin{array}{l}8 \text { of } 25(32.0 \%) \\
8 \text { of } 103(7.8 \%)\end{array}$ & $\begin{array}{c}100 \text { of } 422(23.7 \%) \\
30 \text { of } 463(6.5 \%)\end{array}$ & $\begin{array}{r}100 \text { of } 460(21.7 \%) \\
32 \text { of } 462(6.9 \%)\end{array}$ \\
\hline \multicolumn{4}{|l|}{ Primary analysis of the primary outcome } \\
\hline \multicolumn{4}{|l|}{ Adjusted odds ratio } \\
\hline Mean (SD) & $0.62(0.22)$ & $0.95(0.13)$ & 1 [Reference] \\
\hline Median (95\% credible interval) & $0.58(0.30$ to 1.16$)$ & $0.94(0.72$ to 1.24$)$ & 1 [Reference] \\
\hline \multicolumn{4}{|l|}{ Probability of inferiority to bamlanivimab- } \\
\hline etesevimab, \% & $91 \%$ & - & $34 \%$ \\
\hline Probability of inferiority to casirivimab- & & & \\
\hline imdevimab, \% & $94 \%$ & $66 \%$ & - \\
\hline \multicolumn{4}{|l|}{ Probability of equivalence between } \\
\hline \multirow{2}{*}{\multicolumn{4}{|c|}{$\begin{array}{l}\text { bamlanivimab-etesevimab and casirivimab- } \\
\text { imdevimab within an odds ratio bound of } \%\end{array}$}} \\
\hline & & & \\
\hline 0.25 & - & & \\
\hline 0.20 & - & & \\
\hline 0.15 & - & & \\
\hline 0.10 & - & & \\
\hline 0.05 & - & & \\
\hline
\end{tabular}

* IQR, interquartile range; mAb, monoclonal antibodies; SD, standard deviation. 
FIGURE LEGENDS

\section{Figure 1. Epidemiology of Monoclonal Antibody Infusions.}

483 Panel A shows the number of mAb-infused patients among the EHR screen eligible. Panel B

484 shows the proportion of mAb-infused patients among EHR screen eligible by White or Black

485 race. Hispanic ethnicity, Other, and Unknown race are not shown due to small sample sizes.

486 Panel $\mathrm{C}$ shows the number of mAb infusions per 1,000 cases prior to March 10, 2021. Panel D

487 shows the number of mAb infusions per 1,000 cases after March 10, 2021. Zip codes with $<10$

488 Covid-19 cases or those outside of Pennsylvania are not shown.

490 Interpretive example: Prior to the trial (panel $A$ ), mAb infusion was low. In panel $\mathrm{B}$, the

491 proportion of White and Black race infused among EHR-screen eligible patients increased. In the 492 UPMC catchment in Pennsylvania, mAb infusions also increased in amount (darker, panel C, D) 493 and in geographic distribution (more zip code areas colored) during OPTIMISE-C19.

494 and EUA eligibility criteria over time (Supplement).

\section{Figure 2. CONSORT Diagram.}

Due to pharmacy logistics, 5 patients who received bamlanivimab-etesevimab had been randomly assigned to casirivimab-imdevimab, and 7 patients who received casirivimabimdevimab had been randomly assigned to bamlanivimab-etesevimab. All infused patients who received bamlanivimab monotherapy had been randomly assigned to bamlanivimab monotherapy. The FDA mAb policies changed over time, resulting in varying $\mathrm{mAb}$ availability 
medRxiv preprint doi: https://doi.org/10.1101/2021.09.03.21262551; this version posted September 9, 2021. The copyright holder for this preprint (which was not certified by peer review) is the author/funder, who has granted medRxiv a license to display the preprint in perpetuity.

All rights reserved. No reuse allowed without permission.

\section{Figure 3. Hospital-Free Days to Day 28.}

510

511 Primary outcome is displayed as horizontally stacked proportions by monoclonal antibody type.

512 Red represents worse values and blue represents better values. The median adjusted odds ratio

513 from the primary analysis, using a Bayesian cumulative logistic model, were 0.58 (95\% credible

514 interval, 0.30 to 1.16 ) and 0.94 (95\% credible interval, 0.72 to 1.24 ) for the bamlanivimab and

515 bamlanivimab-etesevimab groups compared with the casirivimab-imdevimab group. These odds

516 ratios yielded $91 \%$ and $94 \%$ probabilities of inferiority of bamlanivimab versus bamlanivimab-

517 etesevimab and casirivimab-imdevimab respectively, and an $86 \%$ probability of equivalence

518 between bamlanivimab-etesevimab and casirivimab-imdevimab at an odds ratio bound of 0.25.

519

520

521

522

523

524

525 
medRxiv preprint doi: https://doi.org/10.1101/2021.09.03.21262551; this version posted September 9, 2021. The copyright holder for this preprint (which was not certified by peer review) is the author/funder, who has granted medRxiv a license to display the preprint in perpetuity.

All rights reserved. No reuse allowed without permission.

A mAb-infused patients among EHR-screen eligible

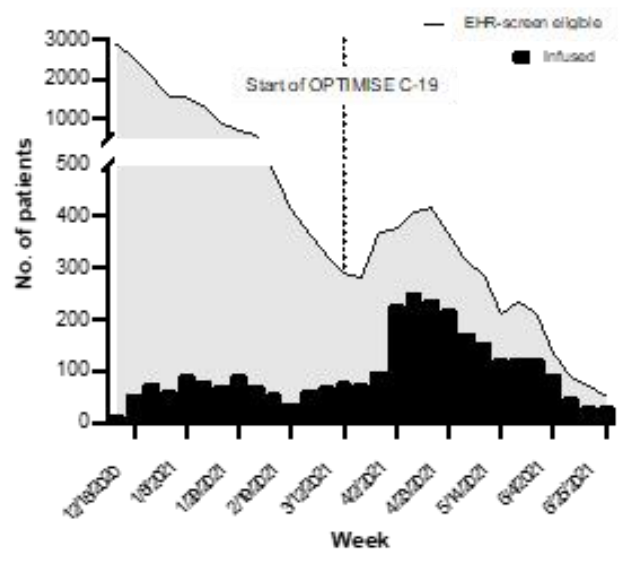

C mAb infusions per 1000 cases prior to March 10 , $2021^{\text {b }}$

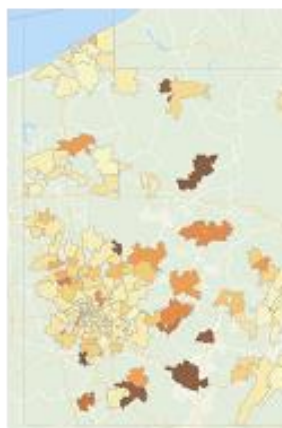

$<10 \quad>300$
B Proportion of mAb-infused patients among EHR screen eligible by White or Black race ${ }^{\text {a }}$

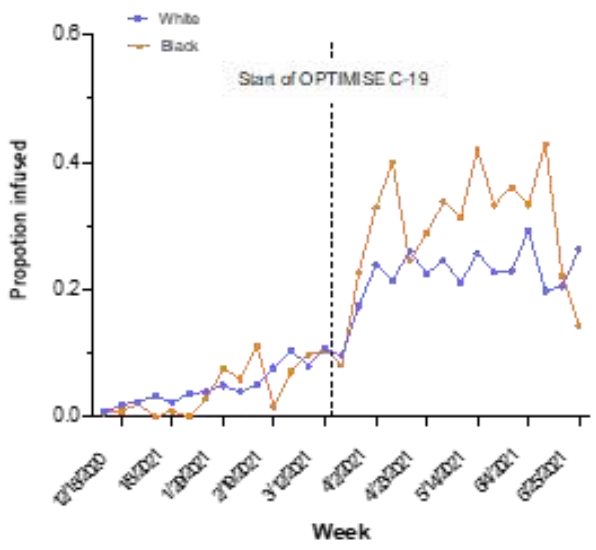

D mAb infusions per 1000 cases after March 10, $2021^{\text {b }}$

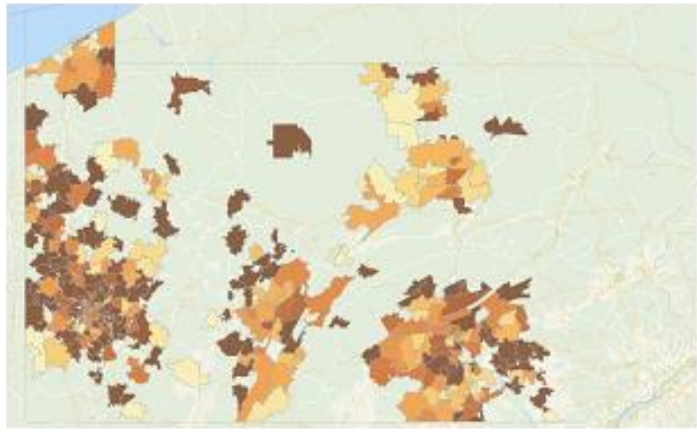

\section{Figure 1. Epidemiology of Monoclonal Antibody Infusions.}


medRxiv preprint doi: https://doi.org/10.1101/2021.09.03.21262551; this version posted September 9, 2021. The copyright holder for this preprint (which was not certified by peer review) is the author/funder, who has granted medRxiv a license to display the preprint in perpetuity.

All rights reserved. No reuse allowed without permission.

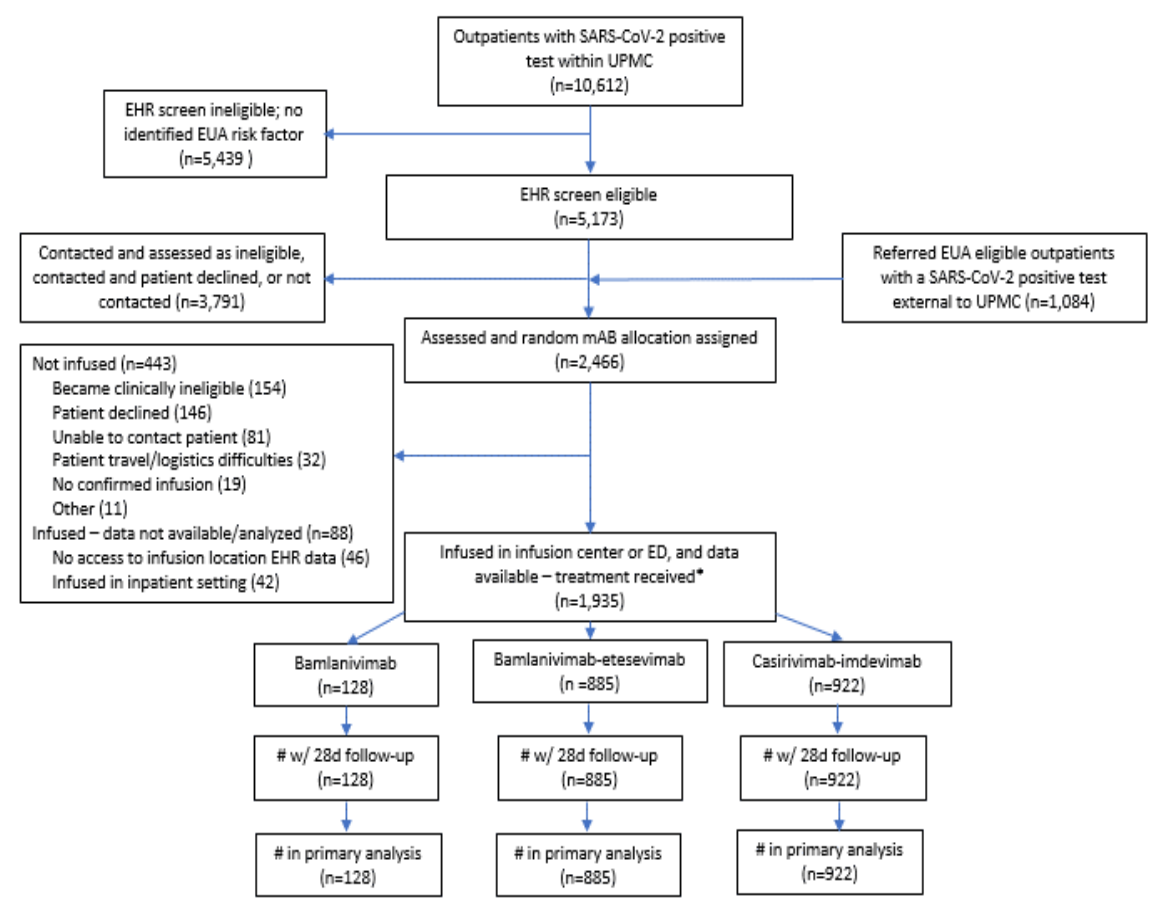

531

Figure 2. CONSORT Diagram.

534

535 
medRxiv preprint doi: https://doi.org/10.1101/2021.09.03.21262551; this version posted September 9, 2021. The copyright holder for this preprint (which was not certified by peer review) is the author/funder, who has granted medRxiv a license to display the preprint in perpetuity.

All rights reserved. No reuse allowed without permission.

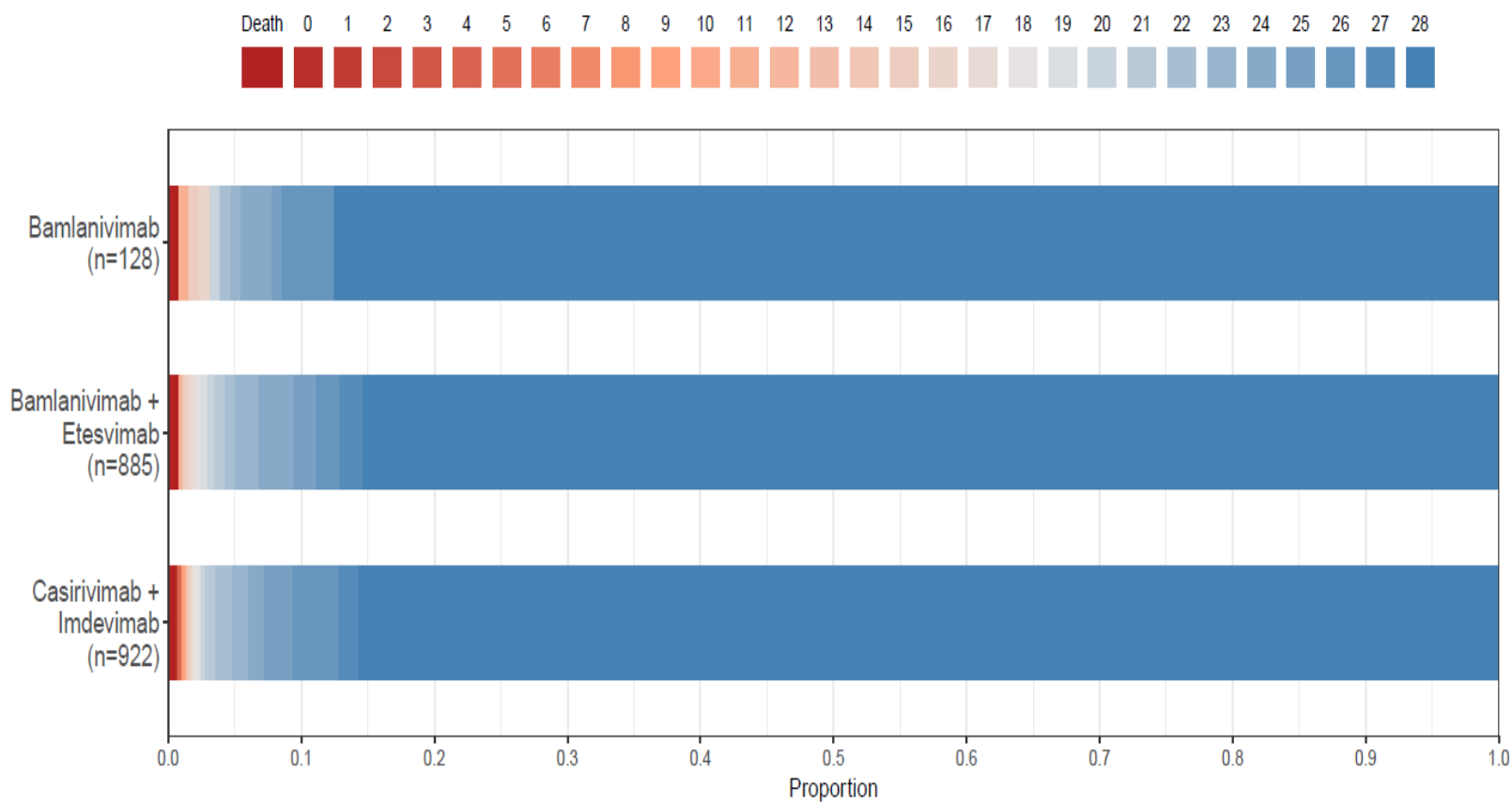


medRxiv preprint doi: https://doi.org/10.1101/2021.09.03.21262551; this version posted September 9, 2021. The copyright holder for this preprint

(which was not certified by peer review) is the author/funder, who has granted medRxiv a license to display the preprint in perpetuity.

All rights reserved. No reuse allowed without permission.

545 This appendix has been provided by the authors to give readers additional information about their 546 work.

548 Supplement to: A learning health system randomized trial of monoclonal antibodies for

\section{Covid-19}

550

551 
552 Table of Contents

553

554

555 Section 1 - Supplementary Methods 3

$556 \quad$ Trial Design

$557 \quad$ Analytical Methods

558

559 Section 2 - Supplementary Tables

560 Table S1. Department of Health and Human Services - Food and Drug Administration's

561 Emergency Use Authorizations and UPMC Monoclonal Antibody Policy Changes Over Time

562 Table S2. Adverse Events in Patients Receiving Monoclonal Antibody Treatment

564 Section 3 - Supplementary Figures

565 Figure S1. Treatment Heterogeneity Across Variant Date Prevalence Epochs

566 Figure S2. SARS-CoV-2 Variants of Concern Proportion in Pennsylvania During the Study

567 Figure S3. Monoclonal Antibody Referral Order in EPIC

$568 \quad$ Figure S4. Monoclonal Antibody Referral Order in Cerner

569

570

571

572

573 


\section{Section 1 - Supplementary Methods}

$576 \quad$ Trial Design: Several problems may be encountered when generating robust clinical

577 evidence, including barriers to conducting clinical trials, the generalisability of data from

578 populations that are too broad or too narrow, the issue of equipoise especially when

579 comparing different types of existing care, and the delay in translating results into clinical

580 practice. A Randomized Embedded Multifactorial Adaptive Platform (REMAP) provides a

581 strategy to address many of these problems by gaining economies of scale from a common

582 platform, which allows for broad enrollment but retaining the ability to examine for

583 heterogeneity of treatment effects between defined subgroups. A REMAP focuses

584 predominantly on the evaluation of treatment options for the disease of interest that are

585 variations within the spectrum of standard care (although testing of novel or experimental

586 therapies is not precluded) and does so by embedding the trial within routine healthcare

587 delivery. In this regard, the REMAP seeks to replace random variation in treatment with

588 randomized variation in treatment allowing causal inference to be generated about the

589 comparative effectiveness of different existing treatment options. The use of response

590 adaptive randomization (RAR), which allows the allocation ratios to change over time based

591 on accruing outcomes data, maximises the chance of good outcomes for trial participants. The

592 embedding of such a platform within the day-to-day activities facilitates the translation of

593 outcomes to clinical practice as a "self-learning" system. As such, it also functions as an

594 embedded and automated continuous quality-improvement program. A final advantage of a

595 REMAP for optimizing monoclonal antibody treatment outcomes is the ability to rapidly

596 adapt to generate evidence if as new interventions emerge, avoiding the inevitable delays

597 associated with conventional trials. 
A REMAP applies novel and innovative trial adaptive design and statistical methods to

599 evaluate a range of treatment options as efficiently as possible. The broad objective of a

600 REMAP is, over time, to determine and continuously update the optimal set of treatments for

601 the disease of interest. The set of treatments that may be tested within a REMAP comprise the

602 set of all treatments that are used currently or may be developed in the future and used or

603 considered for use in patients. The design maximizes the efficiency with which available

604 sample size is applied to evaluate treatment options as rapidly as possible. A REMAP has the

605 capacity to identify differential treatment effects in defined sub-groups (termed strata),

606 address multiple questions simultaneously, and can evaluate interactions among selected

607 treatment options. Throughout the platform, patients who are enrolled in the trial are treated as

608 effectively as possible.

609 A conventional RCT (i.e., a non-platform trial) makes a wide range of assumptions at the time

610 of design. These assumptions include the plausible size of the treatment effect, the incidence

611 of the primary outcome, the planned sample size, the (typically, small number of) treatments

612 to be tested, and that treatment effects are not influenced by concomitant treatment options.

613 These assumptions are held constant until the trial completes recruitment and data are

614 analyzed. Participants who are enrolled in a conventional RCT are not able to benefit from

615 knowledge accrued by the trial because no results are made available until the trial completes.

616 A REMAP uses five approaches to minimise the impact of assumptions on trial efficiency and

617 maximises the benefit of participation for individuals who are enrolled in the trial.

618 These design features are:

619 - frequent adaptive analyses using Bayesian statistical methods

$620 \quad-\quad$ response adaptive randomization 
- evaluation of differential treatment effects in pre-specified sub-groups (strata)

622 - evaluation of specified intervention-intervention interactions

623 - testing of multiple interventions in parallel and, subsequently, in series

624 This creates a 'perpetual trial' with no pre-defined sample size, the objective of which is to

625 define and continuously update best treatment over the lifetime of the REMAP. The design

626 aspects, including the risk of type I and type II errors, are optimized prior to the

627 commencement of the trial by the conduct of extensive pre-trial Monte Carlo simulations,

628 modification of the trial design, and re-simulation in an iterative manner. The methods

629 related to the application of the design features and the statistical analysis of this trial are

630 outlined in the methods section of the protocol. A separate Protocol Appendix contains

631 detailed versions of the protocol with relevant protocol amendments and the statistical

632 analysis plan.

634 Analytical Methods: Within the REMAP, two or more interventions are evaluated, and

635 sequential Bayesian statistical analyses are used over time to incorporate new trial outcome

636 information to determine if an intervention is superior, if one or more interventions are

637 inferior, or if two or more interventions are equivalent, in comparison to all other

638 interventions with respect to the primary endpoint. Every participant will be assigned an

639 intervention. Inference in this REMAP is determined by analyses using pre-specified

640 statistical models that incorporate time periods, age, and disease severity to adjust for

641 heterogeneity of enrolled participants that might influence risk of death. These models

642 incorporate variables that represent each intervention assigned to participants. The efficacy of

643 each intervention is modeled as possibly varying in the different stratum in the REMAP. 
medRxiv preprint doi: https://doi.org/10.1101/2021.09.03.21262551; this version posted September 9, 2021. The copyright holder for this preprint

(which was not certified by peer review) is the author/funder, who has granted medRxiv a license to display the preprint in perpetuity.

All rights reserved. No reuse allowed without permission.

644 Whenever a model hits a predefined threshold for any of superiority, inferiority, or

645 equivalence for an intervention with respect to the primary endpoint, this is termed a

646 statistical trigger. At any given adaptive analysis, a statistical trigger may be reached for all

647 participants or for one or more strata, further described in the statistical analysis plan

648 (Protocol Appendix, page 26).

649 

mAb Emergency Use Authorizations and UPMC Policy Changes Over Time.

\begin{tabular}{|c|c|c|}
\hline Date & Change & Explanation \\
\hline 9-Nov-2021 & $\begin{array}{l}\text { HHS/FDA provides mAb EUAs and } \\
\text { treatment for COVID-19 eligibility } \\
\text { criteria }\end{array}$ & 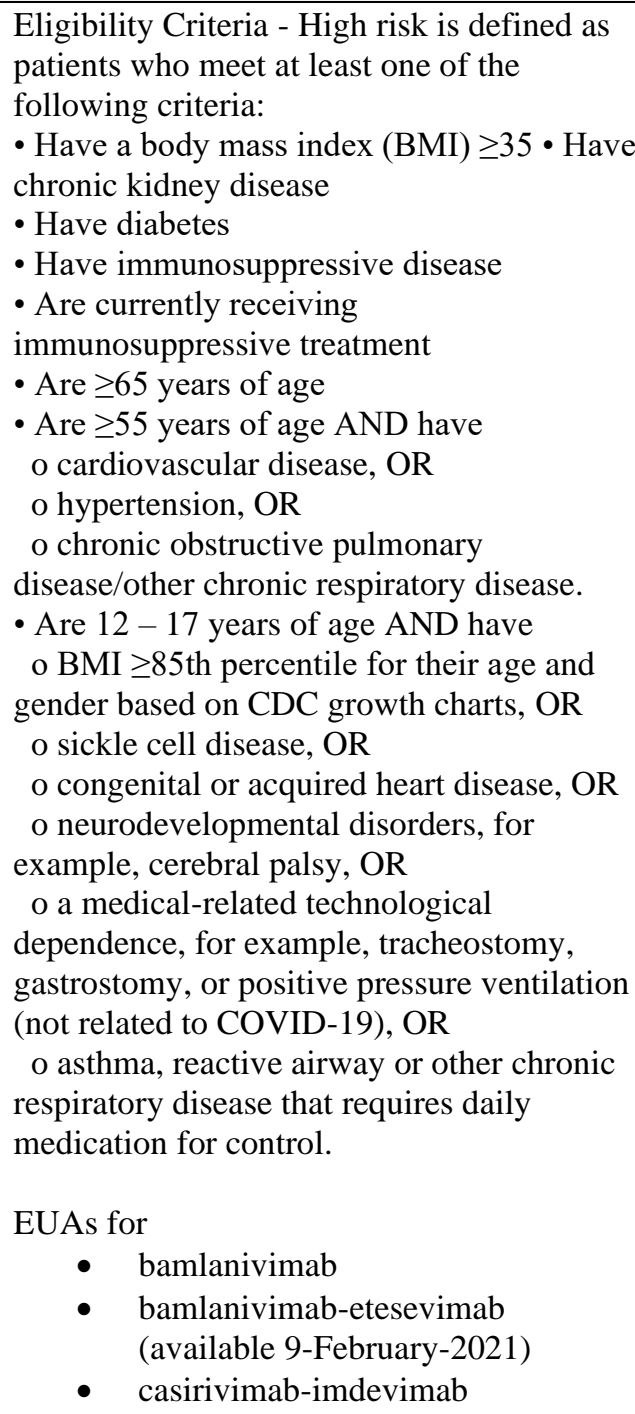 \\
\hline 10-Mar-2021 & UPMC - Opened study enrollment & $\begin{array}{l}\text { Go-live date for trial with bamlanivimab and } \\
\text { casirivimab-imdevimab only and following } \\
\text { COVID-19 Treatment Guidelines. }\end{array}$ \\
\hline 16-Mar-2021 & $\begin{array}{l}\text { UPMC - Incorporation of bamlanivimab- } \\
\text { etesevimab into random allocation }\end{array}$ & $\begin{array}{l}\text { Start incorporating bamlanivimab- } \\
\text { etesevimab into most sites. There was } \\
\text { a } 1 \text {-week delay to use etesevimab at } \\
\text { six sites due to low initial supply. }\end{array}$ \\
\hline
\end{tabular}



$\begin{array}{ll}\text { 23-Mar-2021 } & \text { UPMC - mAb treatment expanded to } \\ \text { Emergency Departments }\end{array}$

\section{5-Mar-2021 HHS/FDA EUA for distribution of bamlanivimab alone was halted}

31-Mar-2021 UPMC - stopped bamlanivimab alone

\section{6-Apr-2021 HHS/FDA EUA for bamlanivimab was revoked}

25-Apr-2021 UPMC - Protocol Amendment 1 to remove use of bamlanivimab alone

26-Apr-2021 UPMC - expanded study enrollment to observation status patients

6-May-2021 UPMC - Interim Analysis

14-May-21 HHS/FDA EUA expands eligibility criteria
Based on published data from our health system demonstrating significant decrease in hospitalizations and deaths with bamlanivimab (Bariola OFID 2021), the decision was made to invest resources in Emergency Department expansion to increase access to $\mathrm{mAb}$ treatment.

A memorandum on the Fact Sheet for bamlanivimab alone - Update was issued on $3 / 17 / 21$. Pseudovirus neutralization data for SARS-CoV-2 variant substitutions with bamlanivimab alone was unsuccessful.

Emerging data about lack of efficacy with SARS-COV-2 variants resulted in System COVID-19 Pharmacy \& Therapeutics Committee's decision to remove bamlanivimab alone from formulary. All sites put on view to use bamlanivimab only with etesevimab.

EUA revoked due to lack of efficacy with SARS-COV-2 variants.

Updated trial protocol to reflect clinical practice of not using bamlanivimab alone.

Established process for treating observation status patients at UPMC hospitals.

Data supported it was safe to proceed.

Eligibility Criteria - The following medical conditions or other factors may place adults and pediatric patients (age 12-17 years and weighing at least $40 \mathrm{~kg}$ ) at higher risk for progression to severe COVID-19:

- Older age (for example age $\geq 65$ years of age)

- Obesity or being overweight (for example, adults with BMI $>25 \mathrm{~kg} / \mathrm{m} 2$ or if age 12-17, have $\mathrm{BMI} \geq 85$ th percentile for their age and gender based on CDC growth charts

- Pregnancy

- Chronic kidney disease

- Diabetes

- Immunosuppressive disease or immunosuppressive treatment - Cardiovascular disease (including congenital heart disease) or hypertension - Chronic lung diseases (for example, chronic obstructive pulmonary disease, asthma [moderate-to-severe], interstitial lung 
26-May-21

\section{HHS/FDA provides an EUA for sotrovimab}

3-June-2021

15-June-2021

\section{HHS/FDA EUA revised to decrease dose for casirivimab-imdevimab}

UPMC - decreased dose for casirivimabimdevimab

25-June-2021 HHS/FDA EUA for distribution of bamlanivimab-etesevimab was paused

25-June-2021 UPMC - stopped bamlanivimab-etesevimab

25-June-2021 UPMC - Protocol Amendment 2: remove bamlanivimab-etesevimab add sotrovimab update EUA expanded eligibility criteria disease, cystic fibrosis, and pulmonary hypertension) $\cdot$ Sickle cell disease - Neurodevelopmental disorders (for example, cerebral palsy) or other conditions that confer medical complexity (for example, genetic or metabolic syndromes and severe congenital anomalies)

- Having a medical-related technological dependence (e.g., tracheostomy, gastrostomy, or positive pressure ventilation [not related to COVID-19])

Sotrovimab is a new $\mathrm{mAb}$ treatment.

Casirivimab 600mg and imdevimab $600 \mathrm{mg}$

Casirivimab-imdevimab dose decreased from $2400 \mathrm{mg}$ to $1200 \mathrm{mg}$.

FDA recommends not to use bamlanivimabetesevimab together.

UPMC pulls from shelves.

Updated trial protocol to reflect clinical practice of not using bamlanivimabetesevimab, add use of sotrovimab, and expanded eligibility criteria.

* mAb, monoclonal antibodies; HHS/FDA, Department of Health and Human 
Table S2. Adverse Events in Patients Receiving Monoclonal Antibody Treatment.

\begin{tabular}{|c|c|c|c|c|}
\hline $\begin{array}{c}\text { Patient } \\
\text { ID }\end{array}$ & $\begin{array}{c}\text { mAb } \\
\text { Received }\end{array}$ & $\begin{array}{c}\text { Mild } \\
\text { Reaction }\end{array}$ & $\begin{array}{c}\text { Severe } \\
\text { Reaction }\end{array}$ & Reaction Description \\
\hline 1 & $\begin{array}{l}\text { Bamlanivimab + } \\
\text { Etesevimab }\end{array}$ & Y & & $\begin{array}{l}\text { Hypoglycemic, hypotension: infusion stopped treated with } \\
\text { diphenhydramine and fluid, patient discharged stable to } \\
\text { home. }\end{array}$ \\
\hline 2 & $\begin{array}{l}\text { Bamlanivimab }+ \\
\text { Etesevimab }\end{array}$ & Y & & $\begin{array}{l}\text { Patient developed tightness in head/sinus area, and } \\
\text { tightness in chest. Infusion not finished. Discharged home. }\end{array}$ \\
\hline 3 & $\begin{array}{l}\text { Bamlanivimab }+ \\
\text { Etesevimab }\end{array}$ & Y & & $\begin{array}{l}\text { Patient reported chest tightness, became lightheaded and } \\
\text { dizzy. Infusion not finished. Discharged home. }\end{array}$ \\
\hline 4 & $\begin{array}{l}\text { Bamlanivimab }+ \\
\text { Etesevimab }\end{array}$ & Y & & $\begin{array}{l}\text { Patient developed hypotension; responded to } 500 \mathrm{~mL} \text { LR, } \\
\text { discharged home normotensive. }\end{array}$ \\
\hline 5 & $\begin{array}{l}\text { Bamlanivimab }+ \\
\text { Etesevimab }\end{array}$ & Y & & Headache, responded to acetaminophen. \\
\hline 6 & $\begin{array}{c}\text { Bamlanivimab }+ \\
\text { Etesevimab }\end{array}$ & Y & & Flushed, chest pain. Stopped infusion. \\
\hline 7 & $\begin{array}{c}\text { Bamlanivimab }+ \\
\text { Etesevimab }\end{array}$ & Y & & $\begin{array}{l}\text { Low back pain, radiating. Decreased infusion rate in half. } \\
\text { Patient stated pain alleviated and denied any complaints }\end{array}$ \\
\hline 8 & $\begin{array}{l}\text { Bamlanivimab }+ \\
\text { Etesevimab }\end{array}$ & $\mathrm{Y}$ & & $\begin{array}{l}\text { Patient reported nausea, hot flash, severe lower back pain } \\
1 \text { minute into infusion. }\end{array}$ \\
\hline 9 & $\begin{array}{c}\text { Bamlanivimab }+ \\
\text { Etesevimab }\end{array}$ & & Y & $\begin{array}{l}\text { Patient stated flushed/throat "closing". Stopped infusion. } \\
\text { Sent to ED for evaluation. }\end{array}$ \\
\hline 10 & $\begin{array}{c}\text { Bamlanivimab }+ \\
\text { Etesevimab }\end{array}$ & Y & & Flushing and shortness of breath. \\
\hline 11 & $\begin{array}{c}\text { Bamlanivimab }+ \\
\text { Etesevimab }\end{array}$ & $\mathrm{Y}$ & & Mild itchiness and redness at infusion site. \\
\hline 12 & $\begin{array}{l}\text { Bamlanivimab }+ \\
\text { Etesevimab }\end{array}$ & $\mathrm{Y}$ & & $\begin{array}{l}\text { Became itchy, developed hives, received } \\
\text { diphenhydramine. }\end{array}$ \\
\hline 13 & $\begin{array}{l}\text { Casirivimab }+ \\
\text { Imdevimab }\end{array}$ & $\mathrm{Y}$ & & Headache. \\
\hline 14 & $\begin{array}{l}\text { Casirivimab }+ \\
\text { Imdevimab }\end{array}$ & & Y & $\begin{array}{l}\text { Sudden onset nausea, vomiting, and weakness after } 1 \text { hour } \\
\text { observation period; checked into ED and admitted post } \\
\text { infusion }\end{array}$ \\
\hline 15 & $\begin{array}{l}\text { Casirivimab }+ \\
\text { Imdevimab }\end{array}$ & $\mathrm{Y}$ & & $\begin{array}{l}\text { Patient developed dizziness and chills which resolved } \\
\text { prior to discharge. }\end{array}$ \\
\hline 16 & $\begin{array}{l}\text { Casirivimab }+ \\
\text { Imdevimab }\end{array}$ & $\mathrm{Y}$ & & $\begin{array}{l}\text { Right before discharge patient mentioned dizziness and } \\
\text { lower blood pressure. Discharged to home. }\end{array}$ \\
\hline 17 & $\begin{array}{l}\text { Casirivimab }+ \\
\text { Imdevimab }\end{array}$ & & $Y$ & $\begin{array}{l}\text { Hypertension and headache post-infusion, transferred to } \\
\text { ED. }\end{array}$ \\
\hline 18 & $\begin{array}{l}\text { Casirivimab }+ \\
\text { Imdevimab }\end{array}$ & & Y & $\begin{array}{l}\text { Patient became hot, red face, reported chest pain } 9 / 10 \text {. } \\
\text { Oxygen saturation went from } 95 \text { to } 85 \text { to } 73 \text {. Sent to ED. }\end{array}$ \\
\hline 19 & $\begin{array}{l}\text { Casirivimab }+ \\
\text { Imdevimab }\end{array}$ & $\mathrm{Y}$ & & $\begin{array}{l}\text { Chills, flushing, chest tightness, headache. Infusion } \\
\text { stopped. }\end{array}$ \\
\hline 20 & $\begin{array}{l}\text { Casirivimab }+ \\
\text { Imdevimab }\end{array}$ & & Y & $\begin{array}{l}\text { Chest pain, shortness of breath, and back pain } 2 \text { minutes } \\
\text { into infusion. Paramedics called. }\end{array}$ \\
\hline 21 & $\begin{array}{l}\text { Casirivimab }+ \\
\text { Imdevimab }\end{array}$ & $Y$ & & $\begin{array}{l}\text { Shortness of breath, chest tightness } 3 \text { minutes into } \\
\text { infusion. Medication stopped and symptoms resolved. }\end{array}$ \\
\hline
\end{tabular}


medRxiv preprint doi: https://doi.org/10.1101/2021.09.03.21262551; this version posted September 9, 2021. The copyright holder for this preprint (which was not certified by peer review) is the author/funder, who has granted medRxiv a license to display the preprint in perpetuity.

All rights reserved. No reuse allowed without permission.

\section{7}

Section 4 - Supplementary Figures

668

$\begin{array}{lllllllllllllllllllllllllllllll}\text { Death } & 0 & 1 & 2 & 3 & 4 & 5 & 6 & 7 & 8 & 8 & 10 & 11 & 12 & 13 & 14 & 15 & 16 & 17 & 18 & 18 & 20 & 21 & 22 & 23 & 24 & 25 & 26 & 27 & 28\end{array}$

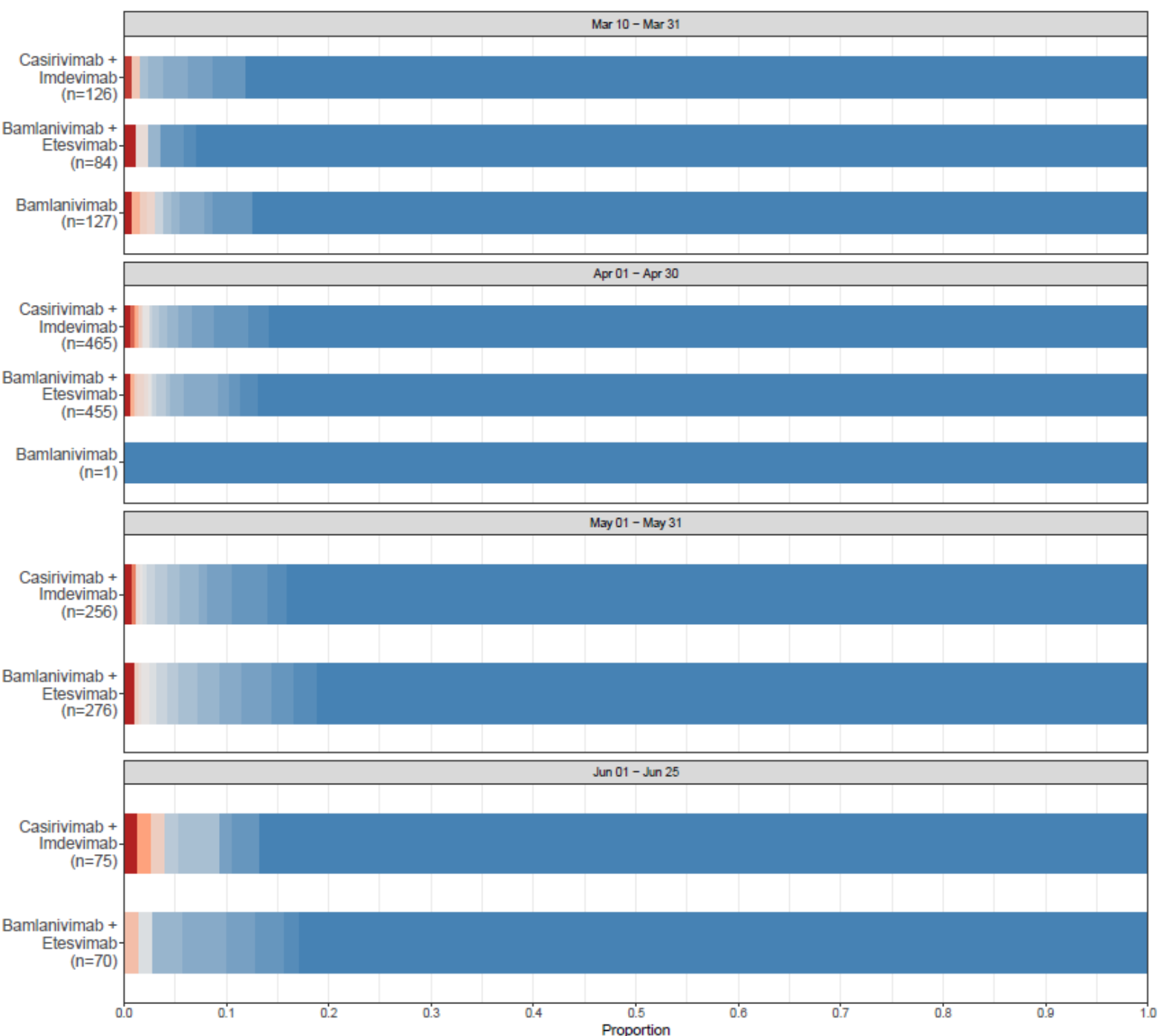

670 Figure S1. Treatment Heterogeneity Across Variant Date Prevalence Epochs.

671

672

673 


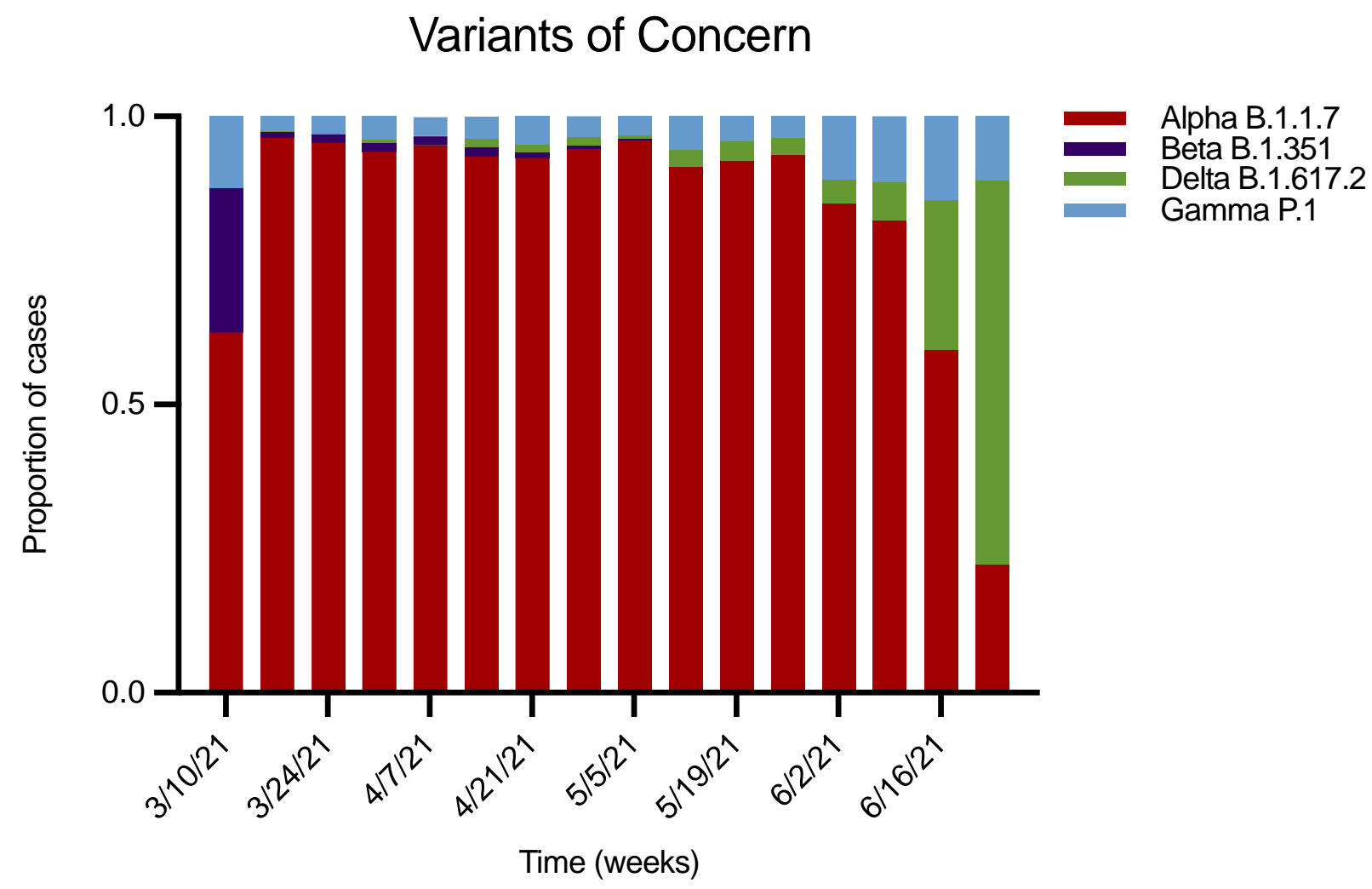


medRxiv preprint doi: https://doi.org/10.1101/2021.09.03.21262551; this version posted September 9, 2021. The copyright holder for this preprint (which was not certified by peer review) is the author/funder, who has granted medRxiv a license to display the preprint in perpetuity.

All rights reserved. No reuse allowed without permission.

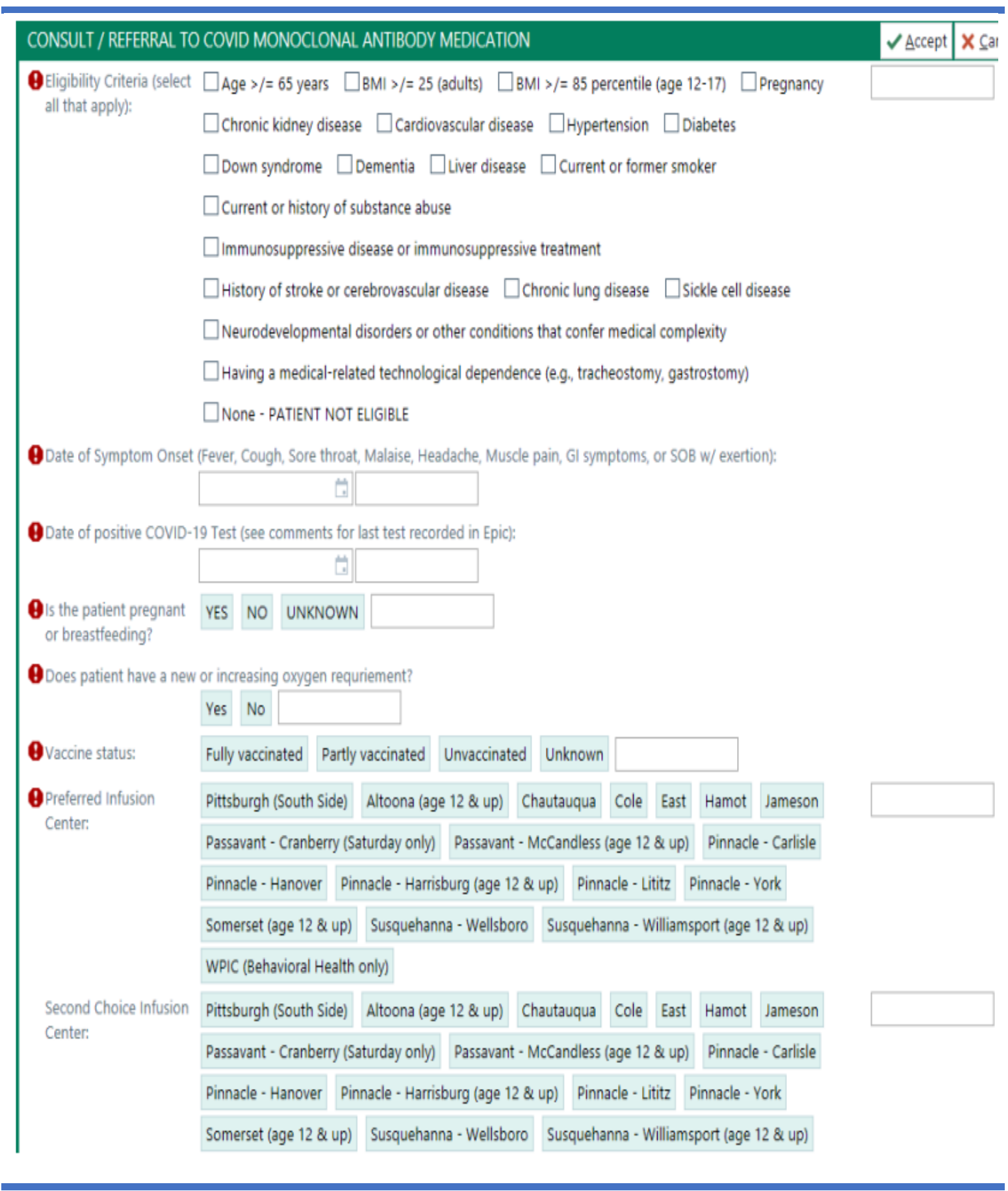


medRxiv preprint doi: https://doi.org/10.1101/2021.09.03.21262551; this version posted September 9, 2021. The copyright holder for this preprint (which was not certified by peer review) is the author/funder, who has granted medRxiv a license to display the preprint in perpetuity.

All rights reserved. No reuse allowed without permission.

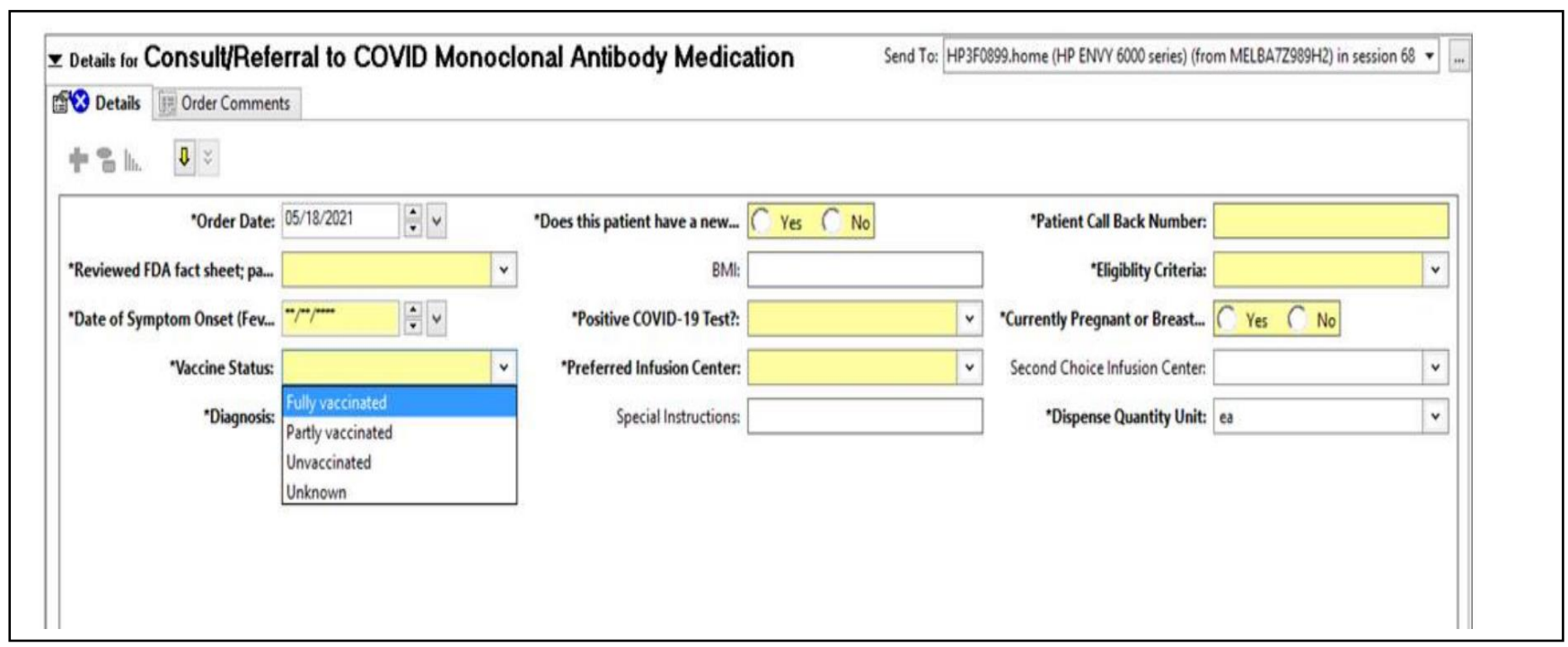

683 Figure S4. Monoclonal Antibody Referral Order in Cerner.

684

685

686

687 
medRxiv preprint doi: https://doi.org/10.1101/2021.09.03.21262551; this version posted September 9, 2021. The copyright holder for this preprint

(which was not certified by peer review) is the author/funder, who has granted medRxiv a license to display the preprint in perpetuity.

All rights reserved. No reuse allowed without permission.

690 This trial protocol has been provided by the authors to give readers additional information about 691 their work.

692

Protocol for: A learning health system randomized trial of monoclonal antibodies for Covid19 
medRxiv preprint doi: https://doi.org/10.1101/2021.09.03.21262551; this version posted September 9, 2021. The copyright holder for this preprint (which was not certified by peer review) is the author/funder, who has granted medRxiv a license to display the preprint in perpetuity.

All rights reserved. No reuse allowed without permission.

695 This appendix contains the following items:

696 1. The original protocol document, final protocol document, and summary of changes.

697 2. The statistical analysis plan.

698

699 Relevant protocol documents included in this supplement are:

700

701

- OPTIMISE-C19 Protocol

702

Original Version 1.0, February $24,2021 \ldots \ldots \ldots \ldots \ldots \ldots \ldots \ldots \ldots \ldots . \ldots \ldots$

703

Final Version 1.2, June 30, 2021

Summary of Changes .25

705 -Amendment 1, Protocol Version 1.1, April 25, 2021

706 -Amendment 2, Protocol Version 1.2, June 30, 2021

707

708

- Statistical Analysis Plan

709

Overall Analysis Plan .26

710

711

- References 
A pragmatic evaluation of monoclonal antibody treatments in participants with COVID-19 illness (ClinicalTrials.gov, NCT04790786)

\section{Summary}

Background

Approach

Treatments

Inclusion

Criteria
- FDA Emergency Use Authorizations (EUA) exist for multiple monoclonal antibodies (mAB) to treat COVID-19; the EUAs stipulate eligibility criteria, patient-physician communication, and clinical monitoring. ${ }^{1}$

- UPMC provides $\mathrm{mABs}$ as routine care; physicians order a $\mathrm{mAB}$ infusion and pharmacies assign whichever $\mathrm{mAB}$ is available under a therapeutic interchange approach. If scarcity exists, a lottery system is used.

- Physicians review with patients the EUA Fact Sheet for each mAB and explain they could be assigned any of the EUA-governed mABs. ${ }^{2-}$

- $\quad$ Structure the therapeutic interchange policy and lottery system using a UPMC pharmacy embedded assignment system that allows a comparative effectiveness evaluation of the multiple mABs. ${ }^{5}$

- Collect data from clinically performed UPMC processes and EUA requirements for routine care.

- Monoclonal antibodies (mAB) for COVID-19

These criteria are as per the FDA EUAs for COVID-19 mABs as of February 24, 2021.

- Adult and pediatric patients (12 years of age and older weighing at least $40 \mathrm{~kg}$ ) with a positive SARS-CoV-2 antigen or PCR test and within 10 days of symptom onset, and high risk of disease progression

- High risk is defined as patients who meet at least one of the following criteria:

$\circ \quad$ Body Mass Index (BMI) $\geq 35$

- Have Chronic Kidney Disease

- Have diabetes

- Have immunosuppressive disease

○ Are currently receiving immunosuppressive treatment

$\circ \quad$ Are $\geq 65$ years of age

$\circ \quad$ Are $\geq 55$ years of age AND have:

O cardiovascular disease, OR

o hypertension, OR

O chronic obstructive pulmonary disease/other chronic respiratory disease

$\circ \quad$ Are 12-17 years of age AND have:

$\circ \quad \mathrm{BMI} \geq 85$ th percentile for their age and gender based on $\mathrm{CDC}$ growth charts, OR 
medRxiv preprint doi: https://doi.org/10.1101/2021.09.03.21262551; this version posted September 9, 2021. The copyright holder for this preprint (which was not certified by peer review) is the author/funder, who has granted medRxiv a license to display the preprint in perpetuity.

All rights reserved. No reuse allowed without permission.
Exclusion These criteria are as per the FDA EUAs for COVID-19 mABs as of February Criteria $\quad 24,2021 .^{1}$

○ $\quad$ sickle cell disease, OR

- congenital or acquired heart disease, OR

○ neurodevelopmental disorders (e.g., cerebral palsy),

OR

- a medical-related technological dependence, for example, tracheostomy or gastrostomy), OR

- asthma, reactive airway, or other respiratory disease that requires daily medication for control.

- Are hospitalized for the treatment of COVID-19

- Require oxygen therapy for the treatment of COVID-19

- Require an increase in baseline oxygen flow rate due to COVID-19 in those on chronic oxygen therapy due to underlying non-COVID-19 related comorbidity

- Have a known hypersensitivity to any antibody ingredient

Primary Total hospital free days at 28 days

evaluation

metric 
Table of Contents

723 1. ABBREVIATIONS

724 2. BACKGROUND and RATIONALE

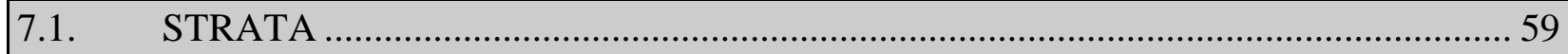

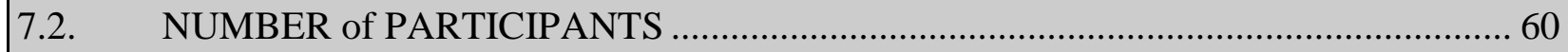

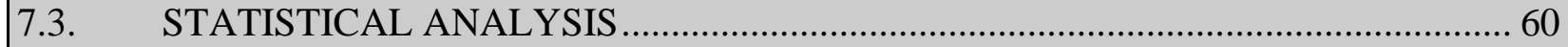

8. ETHICAL CONSIDERATIONS $\quad \ldots . . . .60$




\section{1. ABBREVIATIONS}

765
$\mathrm{AE}$
Adverse Events
B bamlanivimab
$\mathrm{B}+\mathrm{E}$
bamlanivimab and etesevimab
BMI
Body Mass Index
$\mathrm{C}+\mathrm{I}$
casirivimab + imdevimab
$\mathrm{CDC}$
Centers for Disease Control and Prevention
COPD
Chronic Obstructive Pulmonary Disease
COVID-19
Coronavirus disease 2019
CVD
Cardiovascular Disease
EUA
Emergency Use Authorization
FDA
Food and Drug Administration
HHS
Health and Human Services
HFD
Hospital Free Days
HTN
Hypertension
$\mathrm{kDa}$
Kilodaltons
IgG1
$\mathrm{KG}$
Immunoglobulin G1
$\mathrm{mAB}$
Kilograms
PCR
Monoclonal Antibodies
SAEs
Polymerase Chain Reaction
SARS-CoV-
Serious Adverse Events
2
Severe Acute Respiratory Syndrome
UATRC
Coronavirus 2
UPMC Antibody Treatment and Evaluation
Center

\section{2. BACKGROUND and RATIONALE}

\section{BACKGROUND}

770

771 While COVID-19 vaccination will reduce COVID-19-related morbidity and mortality, the learned

772 immune response may vary between individuals. This means interventions such as monoclonal

773 antibodies (mAB) will still be needed to prevent progression of COVID-19 illness. Monoclonal

774 antibodies seek to mimic or enhance the natural immune system response against a pathogen and

775 are often used in the care of patients with cancer or infection. 
776 For viral infections, mABs are created by exposing a white blood cell to a particular viral protein,

777 which is then cloned to mass produce antibodies to target that virus. For SARS-CoV-2, the virus

778 that causes COVID-19, IgG1 mABs target the spike protein of SARS-CoV-2 and block viral

779 attachment and entry into cells.

780 The SARS-CoV-2 mABs bamlanivimab and etesevimab, and the REGN-COV2 combination

781 (casirivimab + imdevimab) reduce nasopharyngeal viral burden plus clinical outcomes including

782 future emergency department visits and hospitalizations (Weinreich 33332778 NEJM, Gottlieb

783 33475701). Each received FDA Emergency Use Authorization (EUA) for use in selected

784 populations (Exhibit). Additional trials of pre-exposure prophylaxis (NCT04497987) and other

785 applications are underway, and additional mABs are in development.

786 The trials demonstrated the greatest impact of the REGN-COV2 dual therapy among patients who 787 lacked neutralizing antibodies against SARS-CoV-2 at baseline and in those with high 788 nasopharyngeal viral loads. Additionally, few patients in the bamlanivimab/etesevimab trial 789 developed treatment-emergent SARS-CoV-2 resistance. This latter phenomenon may further 790 enhance the need for therapies given the recent emergence of SARS-CoV-2 variants that may 791 escape vaccination. However, the relative effectiveness of each $\mathrm{mAB}$ compared to the other is 792 unknown, as is their effectiveness for emerging virus variants.

793 This Appendix to the UPMC Pilot Core (PittPro 20040210) describes the approach of the UPMC 794 Antibody Treatment and Evaluation Center. We will conduct a pragmatic evaluation of 795 monoclonal antibody treatments in participants with COVID-19 illness, starting with the patient 796 population approved under the current FDA mAB EAUs.

\section{RATIONALE}

As of February 2021, there are over 60,000 new cases of COVID-19 diagnosed daily in the US

801 https://covid.cdc.gov/covid-data-tracker/\#trends_dailytrendscases, with over 7000 daily COVID-

80219 related hospital admissions Microsoft Power BI (powerbigov.us). Although case volumes are 803 currently declining, COVID-19 remains a significant public health threat.

804 Despite the EUAs, the clinical use of $\mathrm{mABs}$ is low due in part to lack of patient access, 805 complexities in drug allocation, and lack of knowledge among providers are contributing factors. 806 Further, the comparative effectiveness of different mABs is unknown and not yet directly studied. 807 The National Academies of Sciences, Engineering, and Medicine recently called for expanded 
access and clinical use of mABs, noting it is "critical to collect data and evaluate whether they are

809 working as predicted”.

810 This evaluation seeks to expand access to mABs at UPMC and determine their relative effects

811 versus each other, starting with those governed by EUAs.

\section{OBJECTIVES AND METRICS}

\section{OBJECTIVES}

816

817 The primary objective is to evaluate the clinical and biological effect of multiple monoclonal 818 antibodies (mABs) in patients with COVID-19.

819 The primary hypothesis is clinical and biological effect will vary between mABs, by SARS-CoV-

8202 variants, and patient characteristics.

$8217 . \quad$ METRICS

823 The primary evaluation metric is total hospital free days (HFD) at 28 days after mAB receipt

824 calculated as 28 minus the number of days during the index stay minus the number of days

825 readmitted during the 28 days after treatment. Death within 28 days is recorded as -1 HFD.

826 Secondary evaluation metrics include:

827 - All-cause and all-location mortality at 28 and 90 days

828 - Emergency department visits at 28 days

829 - Organ-support free days at day 28

830 - Where feasible:

831 - SARS-CoV-2 nasopharyngeal and plasma viral loads among participants from baseline and $832 \quad$ longitudinally through day 28

833 - SARS-CoV-2 antibody titers, antibody neutralization, and other immune responses at 834 baseline and longitudinally through day 28

835 - Detection of SARS-CoV-2 variants through next-generation sequencing at baseline and $836 \quad$ longitudinally through day 28

837 - Determining the duration of SAR-CoV-2 infectivity and non-culture surrogates for SARS838 CoV-2 infectivity among patients with persistent nasopharyngeal swab viral shedding 


\section{DESIGN}

841 We will conduct a pragmatic evaluation of participants with COVID-19 illness under existing

842 UPMC processes for the clinical care of COVID-19 positive patients, including EUA requirements

843 for $\mathrm{mAB}$ administration. A patient who presents to a UPMC facility and tests positive for COVID-

84419 will, as per current common care, be offered monoclonal antibodies. Data that are already

845 collected according to UPMC procedures and EUA requirements are used for analysis.

\section{$8479 . \quad$ POPULATION}

We will evaluate patients that present to UPMC Emergency Departments, urgent care sites, infusions centers and other facilities that can or do provide mABs for COVID-19. As of February 24, 2021, there are 3 EUAs, with common inclusion and exclusion criteria, and we will evaluate patients that meet these criteria. As other antibodies become available, we will modify this evaluation submission.

\section{INCLUSION CRITERIA}

As per the current EUA criteria, the following patients are included:

- $\quad$ Adult $(\geq 18$ years old)

- $\quad$ Children $\geq 12$ years old weighing at least $40 \mathrm{~kg}$

861 High risk is defined as patients who meet at least one of the following criteria:

- $\quad$ A Body Mass Index $(\mathrm{BMI}) \geq 35$

- Have chronic kidney disease

- Have diabetes

- Have immunosuppressive disease

- Are currently receiving immunosuppressive treatment

- $\quad$ Are $\geq 65$ years old

- Are $\geq 55$ years of age AND have: 
- Are 12-17 years of age AND have: gastrostomy), OR

○ asthma, reactive airway, or other respiratory disease that requires daily medication for control

\section{EXCLUSION CRITERIA}

As per the current EUA criteria, the following are excluded:

- Are hospitalized for the treatment of COVID-19

- Require oxygen therapy for the treatment of COVID-19

- Require an increase in baseline oxygen flow rate due to COVID-19 in those on chronic oxygen therapy due to underlying non-COVID-19 related comorbidity

- Have a known hypersensitivity to any antibody ingredient

894 physician do not choose a specific $\mathrm{mAB}$ product.

895 As of February 24, 2021, there are three such mABs as listed below.

\section{BAMLANIVIMAB}

8992 identical light chain polypeptides composed of 214 amino acids each and 2 identical heavy chain

900 polypeptides composed of 455 amino acids produced by a Chinese Hamster Ovary (CHO) cell line 901 and molecular weight of $146 \mathrm{kDa}$. 


\section{BAMLANIVIMAB and ETESVIMAB}

Bamlanivimab is a human immunoglobulin G-1 (IgG1 variant) monoclonal antibody consisting of 2 identical light chain polypeptides composed of 214 amino acids each and 2 identical heavy chain polypeptides composed of 455 amino acids produced by a Chinese Hamster Ovary (CHO) cell line and molecular weight of $146 \mathrm{kDa}$.

911 Etesevimab is a human IgG1 variant monoclonal antibody (mAb) consisting of 2 identical light

912 chain polypeptides composed of 216 amino acids each and 2 identical heavy chain polypeptides

913 composed of 449 amino acids produced by a Chinese Hamster Ovary (CHO) cell line and 914 molecular weight of $145 \mathrm{kDa}$.

\section{CASIRIVIMAB and IMDEVIMAB}

Casirivimab, a human immunoglobulin G-1 (IgG1) monoclonal antibody (mAb), is covalent

919 eterotetramer consisting of 2 heavy chains and 2 light chains produced by recombinant DNA 920 technology in Chinese hamster ovary (CHO) cell suspension culture and has an approximate 921 molecular weight of $145.23 \mathrm{kDa}$.

922 Imdevimab, a human IgG1 mAb, is a covalent heterotetramer consisting of 2 heavy chains and 2 923 light chains produced by recombinant DNA technology in Chinese hamster ovary (CHO) cell 924 suspension culture and has an approximate molecular weight of 144.14 kDa.

16. CONCOMITANT THERAPY

927 All care and concomitant therapy are as per the treating providers.

\section{CONDUCT}

\section{DATA COLLECTION}

The EUAs require that healthcare facilities and providers report therapeutic information and 934 utilization data through HHS Protect, Teletracking, or National Healthcare Safety Network as 935 directed by the US Department of Health and Human Services. 
936 We will collect data including baseline demographics and underlying conditions, results of SARS-

937 COV-2 PCR or antibody testing, and initial care including mAB infusion completion. We will

938 collect post-randomization healthcare encounters, including hospitalization, emergency

939 department visits, ICU care, and other measures of healthcare utilization. We will use an electronic

940 health record data collection process to augment existing UPMC data collection processes as

941 necessary.

942 All data will be handled and secured as per University of Pittsburgh and UPMC data guidelines.

943 There will be no research activities involving direct interaction with subjects performed as part of 944 this evaluation.

945 In addition to the primary and secondary outcome data referenced in this submission, data collected

946 will include the below areas. All data will be abstracted directly from the electronic health record 947 and handled anonymously.

948 - Which mAB was administered, including date, time, and infusion completion as well as 949 the location of the infusion

950 - Demographics (including age, sex, race, body weight, vaccination status)

951 - Healthcare encounters, including hospital and ICU admission status if applicable

952 - Medication usage and doses

953 - Hospital and ICU admission status, if applicable

954 - Administration of medications related to COVID-19, if applicable

955 - Remnant blood availability

956 - Laboratory and microbiology data, including COVID-19 testing done for clinical purposes

957 19. BIOSPECIMENS

Where feasible, we will collect discarded remnant blood samples and nasal/oropharyngeal swab samples to quantify the viral load and host response to the virus. As noted under data collection,

961 we will record laboratory and microbiology data performed for clinical purposes.

\section{ANTIBODY ADMINISTRATION}

965 Antibodies will be administered as per the EUAs and UPMC Pharmacy and Therapeutics policies. 966 Providers will explain $\mathrm{mAB}$ risks and benefits and provide the EUA Fact Sheets for Patients, 
Parents and Caregivers

968 as per EUA requirements.

969 21. mAB assignment

971 The COVID-19 mABs are currently routinely used at UPMC. Once any order for mAB infusion

972 is approved by the UPMC system oversight group, the pharmacy provides whichever EUA-

973 governed $\mathrm{mAB}$ is available under a therapeutic interchange approach. Ordering physicians review

974 with the patient the EUA Fact Sheet for each $\mathrm{mAB}$ and explain that the patient could receive any

975 of the mABs governed by FDA EUAs.

976 If demand for $\mathrm{mAB}$ exceeds supply, UPMC has a lottery system to allot who receives the therapy

977 once requested by a physician.

978 Our current proposal is a UPMC system quality improvement initiative, embracing and extending

979 the current lottery system and therapeutic interchange policy for EUA-governed mABs for 980 COVID-19 as follows:

981 1. The Physician orders mAB.

982 a. If scarcity present and lottery system allow provision, proceed.

983 2. The Pharmacy fills order with one of the EUA-governed COVID-19 mABs using an embedded 984 assignment system akin to current mAb provision. This system will allow a comparative 985 effectiveness evaluation of the multiple mABs by effectively ensuring random allocation.

986 3. The Physician can agree to the assigned $\mathrm{mAB}$ or can request a specific mAB.

987 It is the treating physician's choice to accept the assigned $\mathrm{mAB}$ or not, and therefore patient 988 consent for the $\mathrm{mAB}$ assignment is not required. Patients will be told which $\mathrm{mAB}$ they are 989 receiving, along with an EUA Fact Sheet, as per EUA requirements.

\section{STATISTICAL CONSIDERATIONS}

\section{STRATA}

Predefined strata will include patients discharged home after infusion, patients admitted to hospital 997 after infusion, prior vaccination, and if known, presence of virus variants of concern at baseline and presence of neutralizing antibodies to SARS-CoV-2 at baseline. 


\section{NUMBER of PARTICIPANTS}

Sample size is determined by case volume throughout the course of the pandemic.

\section{STATISTICAL ANALYSIS}

1003

The primary evaluation metric is the number of days free from hospitalization to day 28 . We will finalize a statistical analysis plan which will consider $\mathrm{mAB}$ assignment, heterogeneity of treatment effect by patient characteristics and virus variants, and interaction with other treatments. Due to uncertainty in sample size, we will use a Bayesian adaptive design to ensure ability to provide statistical inference despite variable sample size.

\section{ETHICAL CONSIDERATIONS}

\section{DATA MONITORING}

1012

Evaluation center leadership will regularly monitor monthly reports on enrollment, patient 1014 characteristics, and outcomes.

1015 28. CONSENT

1016 As per EUA requirements, physicians will discuss the risks and benefits of mABs and patients will consent to receive a $\mathrm{mAB}$ as part of usual care, should they desire mAB treatment. As per UPMC policy, the ordering physician reviews with patients the EUA Fact Sheet for each $\mathrm{mAB}$ and explain 1019 that the patient could receive any of the mABs governed by FDA EUAs.

\section{ADVERSE EVENTS and SERIOUS ADVERSE EVENTS}

1023 events potentially related to the antibodies within seven calendar days from the onset of the event.

1024 Serious adverse events are defined as death, life-threatening event, inpatient hospitalization or 1025 prolongation of existing hospitalization, substantial disruption of ability to conduct normal life 1026 functions, a congenital anomaly/birth defect, or an intervention to prevent death, a life-threatening 1027 event, hospitalization, disability, or congenital anomaly.

1028 The EUAs require adverse event reports be submitted to FDA MedWatch via one of multiple 1029 methods. Copies of all FDA MedWatch forms are also to be sent to the antibody manufacturer. 
1030 Thus, there already exist reporting requirements for UPMC associated with mAB prescription. We

1031 will track and record these reported data and adverse events by mAB assignment.

1032 30. SAFETY and RISK MITIGATION

1033

1034 The EUAs stipulate warnings including hypersensitivity, clinical worsening, and side effects. As

1035 per EUA requirements, warnings will be communicated by providers to patients, adverse events 1036 will be reported as above, and post-infusion clinical monitoring will be done. Administration of $1037 \mathrm{mABs}$ for patients with COVID-19 is routine care at UPMC, and their administration is not a 1038 research procedure.

1039 31. MANAGEMENT of INFUSION REACTIONS

1040 As per the EUAs, all participants should be monitored closely, as there is a risk of infusion reaction 1041 and hypersensitivity (including anaphylaxis) with any biological agent. Symptoms and signs that 1042 may occur as part of an infusion reaction include, but are not limited to fever, chills, nausea, 1043 headache, bronchospasm, hypotension, angioedema, throat irritation, rash including urticaria, 1044 pruritus, myalgia, and dizziness.

\section{32. EXHIBITS}

EUA fact sheets for health care providers

1048 https://www.fda.gov/media/143603/download

1049 https://www.fda.gov/media/143892/download

1050 https://www.fda.gov/media/145802/download

1051

1052

1053

1054

1055

1056

1057 
A pragmatic evaluation of monoclonal antibody treatments in participants with COVID-19

UPMC OPTIMISE-C19 (Ptimizing Treatment and Impact of

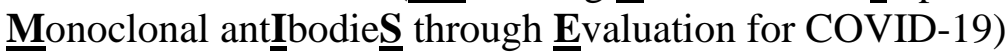
illness (ClinicalTrials.gov, NCT04790786)

\begin{tabular}{|c|c|}
\hline & \\
\hline Background & $\begin{array}{l}\text { - FDA Emergency Use Authorization (EUA) exists for multiple } \\
\text { monoclonal antibodies (mAB) to treat COVID-19; the EUAs stipulate } \\
\text { eligibility criteria, patient-physician communication, and clinical } \\
\text { monitoring. } \\
\text { - UPMC provides mABs as routine care; physicians order a mAB } \\
\text { infusion and pharmacies assign whichever mAB is available under a } \\
\text { therapeutic interchange approach. If scarcity exists, a lottery system is } \\
\text { used. } \\
\text { Physicians review with patients the EUA Fact Sheet for each mAB } \\
\text { and explain they could be assigned any of the EUA-governed mABs. }{ }^{2-} \\
3\end{array}$ \\
\hline Approach & $\begin{array}{l}\text { - Structure the therapeutic interchange policy and lottery system using a } \\
\text { UPMC pharmacy embedded assignment system that allows a } \\
\text { comparative effectiveness evaluation of the multiple mABs. } \\
\text { - Collect data from clinically performed UPMC processes and EUA } \\
\text { requirements for routine care. }\end{array}$ \\
\hline Treatments & - Monoclonal antibodies (mAB) for COVID-19 \\
\hline $\begin{array}{l}\text { Inclusion } \\
\text { Criteria }\end{array}$ & $\begin{array}{l}\text { These criteria are as per the FDA EUAs for COVID-19 mABs as of June } \\
\text { 2021. } \\
\text { - Adult ( } \geq 18 \text { years old) } \\
\text { - Children } \geq 12 \text { years old weighing at least } 40 \mathrm{~kg} \\
\text { - With a positive SARS-CoV-2 antigen or PCR test and within } 10 \text { days } \\
\text { of symptom onset } \\
\text { - High risk of disease progression } \\
\text { High risk is defined as patients who meet at least one of the following criteria: } \\
\text { - Are } \geq 65 \text { years old } \\
\text { - A Body Mass Index (BMI) }>25, \text { or if age } 12-17, \mathrm{BMI} \geq 85^{\text {th }} \text { percentile } \\
\text { - Pregnancy } \\
\text { - Have chronic kidney disease } \\
\text { - Have diabetes } \\
\text { - Have immunosuppressive disease }\end{array}$ \\
\hline
\end{tabular}




\begin{tabular}{|c|c|}
\hline & $\begin{array}{l}\text { - Are currently receiving immunosuppressive treatment } \\
\text { - Cardiovascular disease (including congenital heart disease) or } \\
\text { hypertension } \\
\text { - Chronic lung disease } \\
\text { - } \text { sickle cell disease } \\
\text { - neurodevelopmental disorders (e.g., cerebral palsy) or other conditions } \\
\text { that confer medical complexity (e.g., genetic, or metabolic syndromes } \\
\text { and severe congenital anomalies) } \\
\text { a medical-related technological dependence, for example, } \\
\text { tracheostomy or gastrostomy) } \\
\text { The EUAs note that other medical conditions or factors (for example, race or } \\
\text { ethnicity) may also place individual patients at high risk for progression and } \\
\text { authorization of mAB treatment under the EUA is not limited to the medical } \\
\text { conditions or factors listed above. }\end{array}$ \\
\hline $\begin{array}{l}\text { Exclusion } \\
\text { Criteria }\end{array}$ & $\begin{array}{l}\text { These criteria are as per the FDA EUAs for COVID-19 mABs as of April } \\
\text { 2021. } \\
\text { - Are hospitalized for the treatment of COVID-19 } \\
\text { - Require oxygen therapy for the treatment of COVID-19 } \\
\text { - Require an increase in baseline oxygen flow rate due to COVID-19 in } \\
\text { those on chronic oxygen therapy due to underlying non-COVID-19 } \\
\text { related comorbidity } \\
\text { - Have a known hypersensitivity to any antibody ingredient }\end{array}$ \\
\hline $\begin{array}{l}\text { Primary } \\
\text { evaluation } \\
\text { metric }\end{array}$ & Total hospital free days at 28 days \\
\hline
\end{tabular}


1068 Table of Contents

1069 1. ABBREVIATIONS

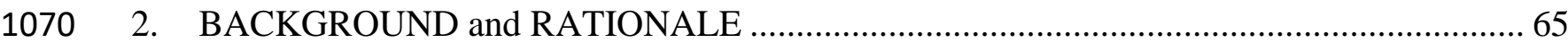

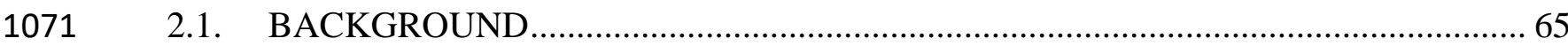

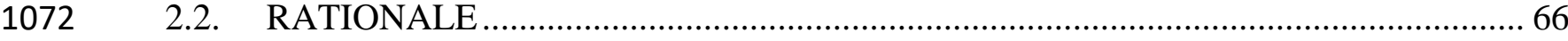

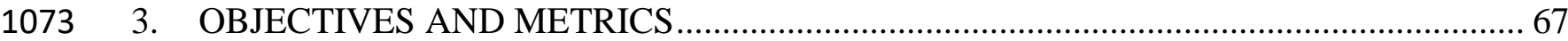

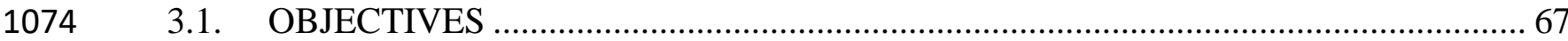

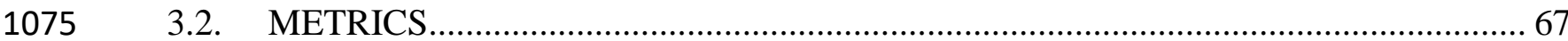

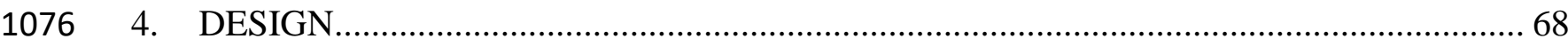

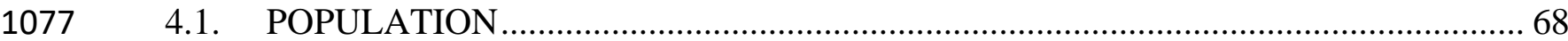

$1078 \quad$ 4.1.1. INCLUSION CRITERIA 68

$1079 \quad$ 4.1.2. EXCLUSION CRITERIA 69

1080

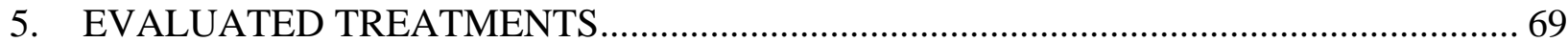

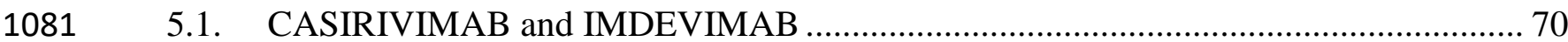

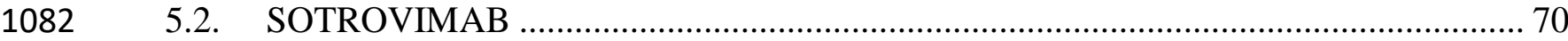

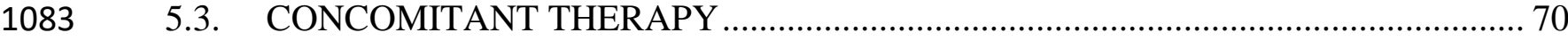

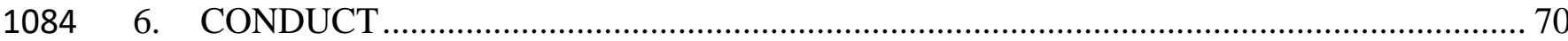

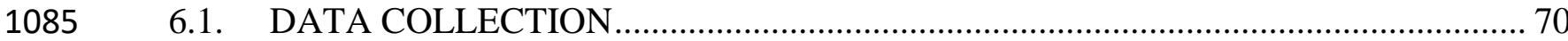

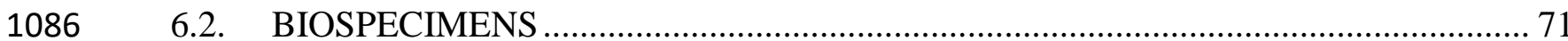

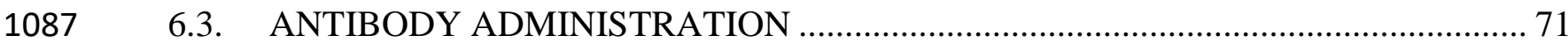

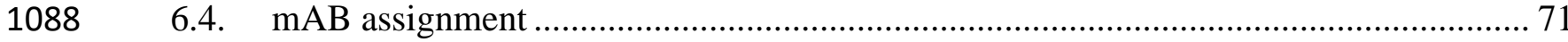

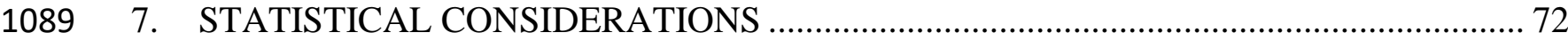

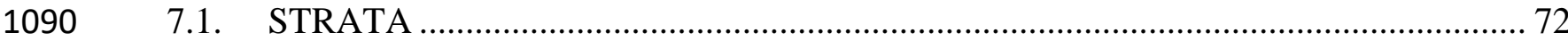

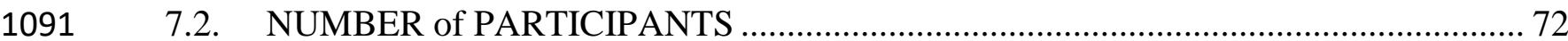

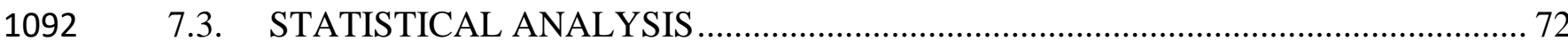

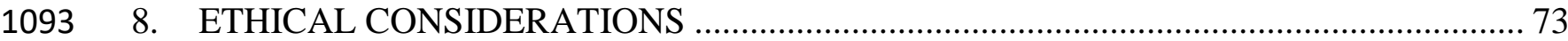

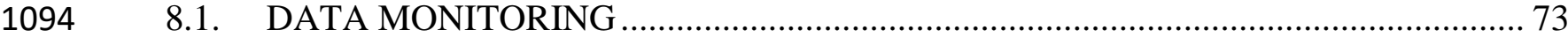

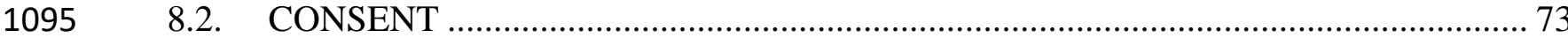

$1096 \quad$ 8.3. ADVERSE EVENTS and SERIOUS ADVERSE EVENTS ................................. 73

$1097 \quad$ 8.3.1. SAFETY and RISK MITIGATION 74

$1098 \quad$ 8.3.2. MANAGEMENT of INFUSION REACTIONS 74

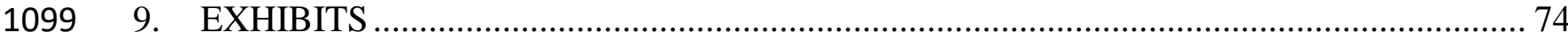

1100 


\section{ABBREVIATIONS}

\begin{tabular}{|c|c|}
\hline $\mathrm{AE}$ & Adverse Events \\
\hline BMI & Body Mass Index \\
\hline $\mathrm{C}+\mathrm{I}$ & casirivimab + imdevimab \\
\hline $\mathrm{CDC}$ & Centers for Disease Control and Prevention \\
\hline COPD & Chronic Obstructive Pulmonary Disease \\
\hline COVID-19 & Coronavirus disease 2019 \\
\hline CVD & Cardiovascular Disease \\
\hline EUA & Emergency Use Authorization \\
\hline FDA & Food and Drug Administration \\
\hline HHS & Health and Human Services \\
\hline HFD & Hospital Free Days \\
\hline HTN & Hypertension \\
\hline $\mathrm{kDa}$ & Kilodaltons \\
\hline IgG1 & Immunoglobulin G1 \\
\hline KG & Kilograms \\
\hline $\begin{array}{l}\text { OPTIMISE- } \\
\text { C19 }\end{array}$ & $\begin{array}{l}\text { OPtimizing Treatment and Impact of } \\
\text { Monoclonal ant Ibodie } \underline{\mathbf{S}} \text { through } \underline{\mathbf{E}} \text { valuation }\end{array}$ \\
\hline $\mathrm{mAB}$ & Monoclonal Antibodies \\
\hline PCR & Polymerase Chain Reaction \\
\hline SAEs & Serious Adverse Events \\
\hline $\begin{array}{l}\text { SARS-CoV- } \\
2\end{array}$ & $\begin{array}{l}\text { Severe Acute Respiratory Syndrome } \\
\text { Coronavirus } 2\end{array}$ \\
\hline UATRC & $\begin{array}{l}\text { UPMC Antibody Treatment and Evaluation } \\
\text { Center }\end{array}$ \\
\hline Vir-7831 & sotrovimab \\
\hline
\end{tabular}

\section{2. BACKGROUND and RATIONALE}

\section{BACKGROUND}

While COVID-19 vaccination will reduce COVID-19-related morbidity and mortality, the learned 1110 immune response may vary between individuals. This means interventions such as monoclonal 1111 antibodies (mAB) will still be needed to prevent progression of COVID-19 illness. Monoclonal 1112 antibodies seek to mimic or enhance the natural immune system response against a pathogen and 1113 are often used in the care of patients with cancer or infection. 
1114 For viral infections, mABs are created by exposing a white blood cell to a particular viral protein,

1115 which is then cloned to mass produce antibodies to target that virus. For SARS-CoV-2, the virus 1116 that causes COVID-19, IgG1 mABs target the spike protein of SARS-CoV-2 and block viral 1117 attachment and entry into cells.

1118 The SARS-CoV-2 mABs bamlanivimab and etesevimab, and the REGN-COV2 combination 1119 (casirivimab + imdevimab) reduce nasopharyngeal viral burden plus clinical outcomes including 1120 future emergency department visits and hospitalizations (Weinreich 33332778 NEJM, Gottlieb 1121 33475701). Each received FDA Emergency Use Authorization (EUA) for use in selected 1122 populations (Exhibit); in April 2021 FDA revoked the EUA for bamlanivimab monotherapy, and 1123 in June 2021 FDA recommended bamlanivimab and etesevimab not be used. Additional trials of 1124 pre-exposure prophylaxis (NCT04497987) and other applications are underway, and additional $1125 \mathrm{mABs}$ are in development.

1126 In May 2021, it was announced that sotrovimab demonstrated clinical efficacy (85\%) in reducing 1127 hospitalizations for more than 24 hours or death in those that received sotrovimab as compared to 1128 placebo (NCT04545060). Subsequently, it received EUA approval in select populations. 1129 Additional trials are underway.

1130 The trials demonstrated the greatest impact of the REGN-COV2 dual therapy among patients who 1131 lacked neutralizing antibodies against SARS-CoV-2 at baseline and in those with high 1132 nasopharyngeal viral loads. Additionally, few patients in the bamlanivimab/etesevimab trial 1133 developed treatment-emergent SARS-CoV-2 resistance. This latter phenomenon may further 1134 enhance the need for therapies given the recent emergence of SARS-CoV-2 variants that may 1135 escape vaccination. However, the relative effectiveness of each $\mathrm{mAB}$ compared to the other is 1136 unknown, as is their effectiveness for emerging virus variants.

1137 This Appendix to the UPMC Pilot Core (PittPro 20040210) describes the approach of the UPMC 1138 OPTIMISE-C19 evaluation. We will conduct a pragmatic evaluation of monoclonal antibody 1139 treatments in participants with COVID-19 illness, starting with the patient population approved 1140 under the current FDA mAB EUAs.

\section{4. RATIONALE}

1144 As of June 2021, there are over 10,000 new cases of COVID-19 diagnosed daily in the US 1145 https://covid.cdc.gov/covid-data-tracker/\#trends_dailytrendscases, with over 1500 daily COVID- 
19 related hospital admissions Microsoft Power BI (powerbigov.us). Although case volumes are

1147 currently declining, COVID-19 remains a significant public health threat.

1148 Despite the EUAs, the clinical use of mABs is low due in part to lack of patient access, 1149 complexities in drug allocation, and lack of knowledge among providers are contributing factors.

1150 Further, the comparative effectiveness of different mABs is unknown and not yet directly studied.

1151 The National Academies of Sciences, Engineering, and Medicine recently called for expanded

1152 access and clinical use of $\mathrm{mABs}$, noting it is "critical to collect data and evaluate whether they are

1153 working as predicted".

1154 This evaluation seeks to expand access to mABs at UPMC and determine their relative effects 1155 versus each other, starting with those governed by EUAs.

\section{OBJECTIVES AND METRICS}

1158

1159

1160

1161

1162

1163

1164

1165

1166

1167

1168

1169

1170

1171

1172

1173

1174

1175

1176

\section{OBJECTIVES}

The primary objective is to evaluate the clinical and biological effect of multiple monoclonal antibodies (mABs) in patients with COVID-19.

The primary hypothesis is clinical and biological effect will vary between mABs, by SARS-CoV2 variants, and patient characteristics.

\section{METRICS}

The primary evaluation metric is total hospital free days (HFD) at 28 days after mAB receipt calculated as 28 minus the number of days during the index stay minus the number of days readmitted during the 28 days after treatment. Death within 28 days is recorded as -1 HFD.

Secondary evaluation metrics include:

- All-cause and all-location mortality at 28 and 90 days

- Emergency department visits at 28 days

- Organ-support free days at day 28

- Where feasible:

- SARS-CoV-2 nasopharyngeal and plasma viral loads among participants from baseline and longitudinally through day 28 
- SARS-CoV-2 antibody titers, antibody neutralization, and other immune responses at baseline and longitudinally through day 28

- Detection of SARS-CoV-2 variants through next-generation sequencing at baseline and longitudinally through day 28

- Determining the duration of SAR-CoV-2 infectivity and non-culture surrogates for SARSCoV-2 infectivity among patients with persistent nasopharyngeal swab viral shedding

\section{DESIGN}

We will conduct a pragmatic evaluation of participants with COVID-19 illness under existing UPMC processes for the clinical care of COVID-19 positive patients, including EUA requirements for $\mathrm{mAB}$ administration. A patient who presents to a UPMC facility and tests positive for COVIDcollected according to UPMC procedures and EUA requirements are used for analysis.

\section{POPULATION}

We will evaluate patients that present to UPMC Emergency Departments, urgent care sites, infusions centers and other facilities that can or do provide mABs for COVID-19. As of June 30, 2021, there are 2 EUAs for COVID-19 mABs, with common inclusion and exclusion criteria, and we will evaluate patients that meet these criteria. As FDA antibody decisions change (E.g., FDA revokes or grants EUAs, or changes eligibility criteria), eligibility criteria will change.

\section{INCLUSION CRITERIA}

As per the current EUA criteria (June 2021), the following patients are included:

- $\quad$ Adult ( $\geq 18$ years old)

- $\quad$ Children $\geq 12$ years old weighing at least $40 \mathrm{~kg}$ 
- A Body Mass Index $(\mathrm{BMI})>25$, or if age $12-17, \mathrm{BMI} \geq 85^{\text {th }}$ percentile

- Pregnancy

- Have chronic kidney disease

- Have diabetes

- Have immunosuppressive disease

- Are currently receiving immunosuppressive treatment

- Cardiovascular disease (including congenital heart disease) or hypertension

1215 - Chronic lung disease

- $\quad$ sickle cell disease

- neurodevelopmental disorders (e.g., cerebral palsy) or other conditions that confer medical complexity (e.g., genetic, or metabolic syndromes and severe congenital anomalies)

1220 The EUAs note that other medical conditions or factors (for example, race or ethnicity) may also 1221 place individual patients at high risk for progression and authorization of $\mathrm{mAB}$ treatment under 1222 the EUA is not limited to the medical conditions or factors listed above.

\section{EXCLUSION CRITERIA}

As per the current EUA criteria (June 2021), the following are excluded:

- Are hospitalized for the treatment of COVID-19

- Require oxygen therapy for the treatment of COVID-19

- Require an increase in baseline oxygen flow rate due to COVID-19 in those on chronic oxygen therapy due to underlying non-COVID-19 related comorbidity

- Have a known hypersensitivity to any antibody ingredient

\section{EVALUATED TREATMENTS}

We will evaluate mABs governed by FDA EUAs. Patients will receive COVID-19 mABs 1234 governed by FDA EUAs, when their treating physician orders a mAB and they meet EUA criteria. 1235 As FDA antibody decisions change (E.g., FDA revokes or grants EUAs, provides full approval, or

1236 changes eligibility criteria), available evaluated treatments will change. In April 2021, FDA 1237 revoked the EUA for bamlanivimab monotherapy and in June 2021 FDA recommended 1238 bamlanivimab and etesevimab not be used. 
As of June 30, 2021, the EUA-approved mABs are as listed below.

13. CASIRIVIMAB and IMDEVIMAB

Casirivimab, a human immunoglobulin G-1 (IgG1) monoclonal antibody (mAb), is covalent eterotetramer consisting of 2 heavy chains and 2 light chains produced by recombinant DNA

1244 technology in Chinese hamster ovary ( $\mathrm{CHO}$ ) cell suspension culture and has an approximate 1245 molecular weight of $145.23 \mathrm{kDa}$.

1246 Imdevimab, a human IgG1 mAb, is a covalent heterotetramer consisting of 2 heavy chains and 2 1247 light chains produced by recombinant DNA technology in Chinese hamster ovary (CHO) cell 1248 suspension culture and has an approximate molecular weight of $144.14 \mathrm{kDa}$.

\section{SOTROVIMAB}

1250

Vir 7831 (sotrovimab) is a recombinant human IgG1k monoclonal antibody that binds to a conserved epitope on the spike protein receptor binding domain of SARS-CoV-2. Sotrovimab does 1253 not compete with human ACE2 receptor binding.

\section{CONCOMITANT THERAPY}

1256 All care and concomitant therapy are as per the treating providers.

\section{CONDUCT}

1259

\section{DATA COLLECTION}

1262 The EUAs require that healthcare facilities and providers report therapeutic information and 1263 utilization data through HHS Protect, Teletracking, or National Healthcare Safety Network as 1264 directed by the US Department of Health and Human Services.

1265 We will collect data including baseline demographics and underlying conditions, results of SARS1266 COV-2 PCR or antibody testing, and initial care including mAB infusion completion. We will 1267 collect post-randomization healthcare encounters, including hospitalization, emergency 1268 department visits, ICU care, and other measures of healthcare utilization. We will use an electronic 1269 health record data collection process to augment existing UPMC data collection processes as 1270 necessary. 
1271 All data will be handled and secured as per University of Pittsburgh and UPMC data guidelines.

1272 There will be no research activities involving direct interaction with subjects performed as part of 1273 this evaluation.

1274 In addition to the primary and secondary outcome data referenced in this submission, data collected

1275 will include the below areas. All data will be abstracted directly from the electronic health record 1276 and handled anonymously.

1277 - $\mathrm{mAB}$ was administered, including date, time, and infusion completion as well as the $1278 \quad$ location of the infusion

- Demographics (including age, sex, race, body weight, vaccination status)

- Healthcare encounters, including hospital and ICU admission status if applicable

- Medication usage and doses

- Hospital and ICU admission status, if applicable

- Administration of medications related to COVID-19, if applicable

- Remnant blood availability

- Laboratory and microbiology data, including COVID-19 testing done for clinical purposes

\section{BIOSPECIMENS}

Where feasible, we will collect discarded remnant blood samples and nasal/oropharyngeal swab samples to quantify the viral load and host response to the virus. As noted under data collection, we will record laboratory and microbiology data performed for clinical purposes.

\section{ANTIBODY ADMINISTRATION}

Antibodies will be administered as per the EUAs, UPMC Pharmacy and Therapeutics policies and the respective Pharmacy Manuals (as generated by the pharmaceutical companies), if applicable.

1296 Providers will explain mAB risks and benefits and provide the EUA Fact Sheets for Patients,

1297 Parents and Caregivers

1298 as per EUA requirements.

1299 20. mAB assignment

The COVID-19 mABs are currently routinely used at UPMC. Once any order for mAB infusion 1302 is approved by the UPMC system oversight group, the pharmacy provides whichever EUA1303 governed $\mathrm{mAB}$ is available under a therapeutic interchange approach. Ordering physicians review 
1304 with the patient the EUA Fact Sheet for each mAB and explain that the patient could receive any 1305 of the mABs governed by FDA EUAs.

1306 If demand for mAB exceeds supply, UPMC has a lottery system to allot who receives the therapy 1307 once requested by a physician.

1308 Our current proposal is a UPMC system quality improvement initiative, embracing and extending 1309 the current lottery system and therapeutic interchange policy for EUA-governed mABs for 1310 COVID-19 as follows:

1311 1. The Physician orders mAB.

a. If scarcity present and lottery system allow provision, proceed.

1313 2. The Pharmacy fills order with one of the EUA-governed COVID-19 mABs using an embedded 1314 assignment system akin to current mAb provision. This system will allow a comparative 1315 effectiveness evaluation of the multiple mABs by effectively ensuring random allocation.

1316 3. The Physician can agree to the assigned $\mathrm{mAB}$ or can request a specific $\mathrm{mAB}$.

1317 It is the treating physician's choice to accept the assigned $\mathrm{mAB}$ or not, and therefore patient 1318 consent for the $\mathrm{mAB}$ assignment is not required. Patients will be told which $\mathrm{mAB}$ they are 1319 receiving, along with an EUA Fact Sheet, as per EUA requirements.

\section{STATISTICAL CONSIDERATIONS}

\section{STRATA}

Predefined strata will include patients discharged home after infusion, patients admitted to hospital 1328 after infusion, prior vaccination, and if known, presence of virus variants of concern at baseline 1329 and presence of neutralizing antibodies to SARS-CoV-2 at baseline.

1332 Sample size is determined by case volume throughout the course of the pandemic.

1333 24. STATISTICAL ANALYSIS 
1335 The primary evaluation metric is the number of days free from hospitalization to day 28 . We will

1336 finalize a statistical analysis plan which will consider mAB assignment, heterogeneity of

1337 treatment effect by patient characteristics and virus variants, and interaction with other

1338 treatments. Due to uncertainty in sample size, we will use a Bayesian adaptive design to ensure

1339 ability to provide statistical inference despite variable sample size.

\section{ETHICAL CONSIDERATIONS}

\section{DATA MONITORING}

UPMC clinical leadership will regularly monitor monthly reports on enrollment, patient 1345 characteristics, and outcomes. Leadership will also receive regular interim analyses from the 1346 adaptive statistical model to inform UPMC clinical policy.

\section{CONSENT}

1348 As per EUA requirements, physicians will discuss the risks and benefits of $\mathrm{mABs}$ and patients will 1349 consent to receive a mAB as part of usual care, should they desire mAB treatment. As per UPMC 1350 policy, the ordering physician reviews with patients the EUA Fact Sheet for each $\mathrm{mAB}$ and explain 1351 that the patient could receive any of the mABs governed by FDA EUAs.

1352 28. ADVERSE EVENTS and SERIOUS ADVERSE EVENTS

1354 The EUAs require providers and/or their designees report all medication errors and serious adverse 1355 events potentially related to the antibodies within seven calendar days from the onset of the event. 1356 Serious adverse events are defined as death, life-threatening event, inpatient hospitalization or 1357 prolongation of existing hospitalization, substantial disruption of ability to conduct normal life 1358 functions, a congenital anomaly/birth defect, or an intervention to prevent death, a life-threatening 1359 event, hospitalization, disability, or congenital anomaly.

1360 The EUAs require adverse event reports be submitted to FDA MedWatch via one of multiple 1361 methods. Copies of all FDA MedWatch forms are also to be sent to the antibody manufacturer. 1362 Thus, there already exist reporting requirements for UPMC associated with mAB prescription. We 1363 will track and record these reported data and adverse events by mAB assignment. 


\section{SAFETY and RISK MITIGATION}

The EUAs stipulate warnings including hypersensitivity, clinical worsening, and side effects. As

1367 per EUA requirements, warnings will be communicated by providers to patients, adverse events

1368 will be reported as above, and post-infusion clinical monitoring will be done. Administration of mABs for patients with COVID-19 is routine care at UPMC, and their administration is not a research procedure.

\section{$137130 . \quad$ MANAGEMENT of INFUSION REACTIONS}

1372 As per the EUAs, all participants should be monitored closely, as there is a risk of infusion reaction

1373 and hypersensitivity (including anaphylaxis) with any biological agent. Symptoms and signs that 1374 may occur as part of an infusion reaction include, but are not limited to fever, chills, nausea, 1375 headache, bronchospasm, hypotension, angioedema, throat irritation, rash including urticaria, 1376 pruritus, myalgia, and dizziness.

\section{EXHIBITS}

1378

1379

1380

1381

1382

1383

1384

1385

1386

1387

1388

1389

1390

1391

1392

1393
EUA fact sheets for health care providers

https://www.fda.gov/media/149534/download (sotrovimab)

https://www.regeneron.com/downloads/treatment-covid19-eua-fact-sheet-for-hcp.pdf

(casirivimab and imdevimab) 
OPTIMISE-C19 - Summary of Changes for Amendment 1 on April 25, 2021:

\begin{tabular}{|l|l|l|}
\hline Page \# & Protocol Section & Reason for Change \\
\hline 1 & Protocol Title Page & $\begin{array}{l}\text { Title Changed to reflect new abbreviation being used for } \\
\text { study }\end{array}$ \\
\hline $2-3$ & Summary table & Summary table updated to reflect protocol changes \\
\hline 10 & 4.1 & $\begin{array}{l}\text { Clarification added to section 4.1 to reflect changing } \\
\text { landscape of FDA EUA authorization and revocation }\end{array}$ \\
\hline 12 & 5 & $\begin{array}{l}\text { Clarification added to section 5 to reflect changing } \\
\text { landscape of FDA EUA authorization and revocation }\end{array}$ \\
\hline 12 & 5.1 & $\begin{array}{l}\text { Removed Section 5.1 Bamlanivimab due to EUA being } \\
\text { revoked by the FDA }\end{array}$ \\
\hline 17 & 8.1 & $\begin{array}{l}\text { Updated to provide more detail on the monitoring of data } \\
\text { by UPMC clinical leadership }\end{array}$ \\
\hline 18 & 9 & EUA for Bamlanivimab removed \\
\hline
\end{tabular}

\section{\begin{tabular}{|l|l|l} 
Page \# & Protocol Section & Reason for Change
\end{tabular}}

\begin{tabular}{|l|l|l|}
\hline NA & NA & $\begin{array}{l}\text { Minor administrative changes throughout the } \\
\text { document to reflect Amendment \#2 documentation }\end{array}$ \\
\hline $2-3$ & Summary table & Summary table updated to reflect protocol changes \\
\hline 7 & 2.1. & Information regarding new monoclonal antibody \\
\hline 7 & 2.1. & $\begin{array}{l}\text { Information added regarding the revocation of EUA } \\
\text { approved of bamlanivimab and etesvimab }\end{array}$ \\
\hline 8 & 2.2. & Information added to reflect current COVID trends \\
\hline $10-11$ & 4.1 .1$. & Updated Inclusion Criteria as per EUA requirements \\
\hline 12 & 5 & $\begin{array}{l}\text { Information added regarding the revocation of EUA } \\
\text { approved of Bamlanivimab }\end{array}$ \\
\hline 12 & 5.1. & Removal of section 5.1. - bamlanivimab and etesvimab \\
\hline $12-13$ & 5.2. & Addition of newly approved monoclonal antibody - \\
\hline 15 & 6.3. & $\begin{array}{l}\text { Information added to reflect UPMC will utilize a } \\
\text { pharmacy manual if provided by the drug }\end{array}$ \\
\hline 19 & 9.0. & $\begin{array}{l}\text { Exhibits added and removed to reflect current EUA } \\
\text { approved monoclonal antibodies }\end{array}$ \\
\hline
\end{tabular}




\section{Introduction}

1413

1414

1415

1416

1417

1418

1419

1420

1421

1422

1423

1424

1425

1426

1427

1428

1429

1430

1431

1432

1433

1434

1435

1436

1437

1438

1439

1440

1441

1442

1443

1444

1445

This document describes the detail of the analysis read-out from July 26, 2021. This document is an appendix to the Statistical Analysis Plan for the "UPMC Antibody Treatment and Evaluation Center" with the details for this analysis read-out.

- We will analyze and report three treatment arms (below) as the first two have been administratively closed to enrollment due to FDA decisions.

- Unblinded data from this and prior interim analyses can be shared with investigators after the last randomized allocations (June 25) to the two mAB treatment arms closed by FDA.

- This unblinding is appropriate as future analyses of patients randomized to the third arm $(\mathrm{C}+\mathrm{I})$ will not be compared to the first two arms, there are no "control" arms as all patients receive $\mathrm{mAB}$ treatment, and future comparisons will be of $\mathrm{C}+\mathrm{I}$ vs newer mABs.

- Enrollment continues in the currently available treatment arms ( $\mathrm{C}+\mathrm{I}$ and $\mathrm{S})$. "S" refers to sotrovimab, produced by GSK and Vir.

\section{Treatment Arms}

There are three treatment arms that will be included in this analysis. The treatment arms are

1. B (Bamlanivimab)

2. $\mathrm{B}+\mathrm{E}$ (Bamlaniviman/Etesevimab combination)

3. $\mathrm{C}+\mathrm{I}$ (casirivimab/imdevimab combination)

\section{Primary Endpoint}

The primary endpoint for this read-out is hospital-free days.

\section{Primary Analysis Population}

The primary analysis population for this read-out is the "As-Infused" population. This analysis will include each patient randomized from March 10, 2021 until June 25, 2021. The date of the data set snapshot is on July 26, 2021.

\section{Primary Analysis Model}

The primary analysis model is as described in the trial SAP.

The primary analysis for the primary endpoint is a cumulative proportional odds model. Let the probability of an outcome of less than or equal to y be $\pi_{y}=\operatorname{Pr}(Y \leq y)$. Let $a$ be the indicator of treatment arm $(a=1, \ldots, \mathrm{k})$. The model adjusts for the following baseline variables: 
1. ED or infusion center $(0=$ infusion center, $1=\mathrm{ED})$

2. Age (with categories of $<30,30-39,40-49,50-59,60-69,70-79$, and $\geq 80$; 60-69 will be used as the referent)

3. Sex (sex at birth, male is the referent)

4. Covid variant is not modeled in this primary analysis

5. Time (two-week epochs of time are used for adjustments; the most current 4-week period is the referent)

The primary analysis model is based on a cumulative logistic regression, where $\pi_{y}=\operatorname{Pr}(Y \leq y)$, where

$$
\log \left(\frac{\pi_{y}}{1-\pi_{y}}\right)=\alpha_{y}-\theta_{a} \delta_{[a]}-\sum_{v=1}^{4} \beta_{v j} \delta_{v j}-\lambda_{[\text {time }]} ; y=-1,0,1,2, \ldots 27
$$

The additive covariate effects across all treatment arms for each patient are modeled through the $\beta$ parameters. The $\delta$ parameters are indicator functions for the treatment arm and covariate values for the baseline covariates. The efficacy of the treatment arms is modeled with the $\theta$ parameters. The ordinal effect parameters $\left(\alpha_{y}\right)$ are modeled with a Dirichlet distribution with equal weight on each outcome and a sum of 1 .

The baseline covariate effects are modeled with independent weak prior distributions:

$$
\beta_{v j} \sim N\left(0,10^{2}\right), v=1, \ldots, 4 ; j=1, \ldots, n_{v} .
$$

The appropriate coefficients will be set to 0 within each covariate for identifiability (the goal will be the largest category set to 0 ).

The effects of time are adjusted within the model using two-week epochs and a smoothing model over time. The modeling of the time effects is set up with the most current period ( 2 epochs combined being the most recent month are set to 0 ):

$$
\begin{gathered}
\lambda_{1} \equiv \lambda_{2} \equiv 0 \\
\lambda_{2}-\lambda_{1} \sim N\left(0,0.15^{2}\right) \\
\lambda_{T}-2 \lambda_{T-1}+\lambda_{T-2} \sim N\left(0, \tau_{\lambda}^{2}\right) ; T \geq 3 \\
\tau_{\lambda}^{2} \sim \operatorname{IG}(0.25,0.00562)
\end{gathered}
$$

The prior distributions for the $\mathrm{mAB}$ treatment effects are weak:

$$
\theta_{a} \sim N(0,10), a=1,2,3 \text {. }
$$


Given the complexity of the model, conventions may be taken by the analysis team if there are convergence issues or model stability issues. For example, there may be outcome categories in the 30 possible primary outcome values (e.g., k number of hospital-free days, patient death) that do not occur. If this happens at analysis, the cells will be combined to achieve model convergence. For example, if the 4 hospital-free day outcome value does not occur it will be combined with 3 , and so on, until every cell has occurred. Additional model stability conventions will be taken to preserve the model stability.

\section{Missing and Partial Data}

If there are missing covariates for a patient in the as-infused patient population, the following conventions will be used.

1. If the treatment arm is missing the patient will be ignored.

2. If a baseline covariate is missing the referent value for that covariate will be used

For all model analyses, only patients who have achieved 28-days of follow-up from the date of with less than 28 days will be conducted.

Given the HER-based data summaries there will be no missing outcome data. If there is deemed hospitalization-free days that at subsequent analyses are found to have out of system hospitalizations. The data will be updated at future analyses.

\section{Trial Inferences}

For the primary analysis, there is no "control" treatment and so all inferences are made comparing the individual treatment arms to each other. The main quantity of interest will be the relative odds ratio between any two treatments arms

$$
O R_{i j}=\exp \left(\theta_{i}\right) / \exp \left(\theta_{j}\right)
$$

The posterior probability that the odds ratio for arm $i$ compared to arm $j$ is greater than 1 (signifying that treatment $i$ is superior to treatment $j$ ) is used as a comparison between arms. Additionally, the posterior mean and $95 \%$ confidence interval between arms will be used to summarize relative treatment effects.

1531

Arm Inferiority: If one of the arms has a 99\% chance of being inferior to any of the other available arms then the inferior arm will be declared inferior and may be removed from the trial. There may be conditions of the pandemic (variation frequency, new variations) or drug supply concerns that an arm is retained.

Equivalence: Any two arms in the trial may reach a declaration of equivalence. It is anticipated that no actions would take when equivalence is reached but a declaration and public disclosure may be made. There is a sliding scale of equivalence with different levels of equivalence bounds. 
A declaration of equivalence will be tied to the equivalence level. Equivalence with a bound of $d$ is declared if the posterior probability of the odds ratio is with $d$ is at least $95 \%$ :

$$
\operatorname{Pr}\left(\frac{1}{1+\delta} \leq O R_{i j} \leq 1+\delta\right) \geq 0.95
$$

The following levels are pre-defined:

1. The first level of equivalence occurs when there is $95 \%$ posterior probability that the odds-ratio is within a bound of $\mathrm{d}=0.25$

2. The second level of equivalence occurs when there is a $95 \%$ posterior probability that the odds-ratio is within a bound of $\mathrm{d}=0.20$

3. The third level of equivalence occurs when there is a $95 \%$ posterior probability that the odds-ratio is within a bound of $\mathrm{d}=0.15$

4. The fourth level of equivalence occurs when there is a $95 \%$ posterior probability that the odds-ratio is within a bound of $\mathrm{d}=0.10$

5. The fifth level of equivalence occurs when there is a $95 \%$ posterior probability that the odds-ratio is within a bound of $\mathrm{d}=0.05$

Combination Futility: For comparing $\mathrm{B}+\mathrm{E}$ to $\mathrm{B}$ the combination $(\mathrm{B}+\mathrm{E})$ will be compared to the individual component arm (B). If there is more than a $95 \%$ probability that the effect of the combination $\mathrm{B}+\mathrm{E}$ is no better than a $20 \%$ improvement in the odds ratio compared to $\mathrm{B}$, then the combination will be declared not clinically relevantly superior (combination futile) to $\mathrm{N}$.

\section{Modeling Treatment Heterogeneity Across Variant Date Prevalence Epochs}

For this read out, the following time epochs will be modeled with different treatment effects using the Treatment Heterogeneity analysis model.

The treatment effect, $\theta_{a}$, will be modeled separately within each epoch, $s=1, \ldots, S$, as $\theta_{a 1}, \theta_{a 2}, \ldots, \theta_{a s}$, with hierarchical prior distribution:

$$
\begin{gathered}
\theta_{a s} \sim N\left(\mu_{a}, \tau_{a}{ }^{2}\right), a=1, \ldots, 3 ; s=1, \ldots, S . \\
\mu_{a} \sim N\left(0,10^{2}\right) ; \tau_{a}^{2} \sim \operatorname{IG}(0.25,0.1) .
\end{gathered}
$$

The following time epochs are specified:

1. March 10 - March 31

2. April $1-$ April 30

3. May 1 - May 31

4. June $1-$ June 25

Specific Analyses

\begin{tabular}{|l|l|l|l|l|}
\hline$\#$ & Status & Population & Endpoint & Other \\
\hline
\end{tabular}




\begin{tabular}{|l|l|l|l|l|}
\hline $\mathbf{1}$ & Primary & $\begin{array}{l}\text { As-Infused to B, B+I, or } \\
\text { C+I on or before June } \\
25,2021\end{array}$ & HFD & \\
\hline $\mathbf{2}$ & $\begin{array}{l}\text { Variant } \\
\text { Secondary }\end{array}$ & $\begin{array}{l}\text { As-Infused to B, B+I, or } \\
\text { C+I on or before June } \\
25,2021\end{array}$ & HFD & $\begin{array}{l}\text { Differential efficacy by } \\
\text { time epoch specified }\end{array}$ \\
\hline
\end{tabular}

1575

1576

1577

1578

1579

1580

1581

1582

1583

1584

1585

1586

1587

1588

1589

The primary analysis

The following posterior probabilities will be reported

\begin{tabular}{|l|l|}
\hline Quantity of Interest & Posterior Probability \\
\hline B+E superior to B & \\
\hline B+E combination futile to B & \\
\hline C+I superior to B & \\
\hline C+I superior to B+E & \\
\hline
\end{tabular}

Statistical Triggers Met for Equivalence with delta ranges of equivalence.

The following will be reported:

\begin{tabular}{|l|l|l|l|l|}
\hline $\begin{array}{l}\text { Odds-Ratio } \\
\text { Parameter }\end{array}$ & Mean & SD & Median & $\begin{array}{l}\text { 95\% Credible } \\
\text { Interval }\end{array}$ \\
\hline Age < 30 & & & & \\
\hline Age 30-39 & & & & \\
\hline Age 40-49 & & & & \\
\hline Age 50-59 & 1 & & & \\
\hline Age 60-69 & & & & \\
\hline Age 70-79 & & & & \\
\hline Age 80+ & & & & \\
\hline Female & & & & \\
\hline Time Bucket 1 & & & & \\
\hline$\ldots$ & & & & \\
\hline Time Bucket k-1 & 1 & & & \\
\hline Referent Arm & & & & \\
\hline Arm \#2 & & & & \\
\hline Arm \#3 & & & & \\
\hline Arm \#2/Arm \#3 & & & \\
\hline
\end{tabular}

\section{Graphical summaries}

1. Stacked bar plots and cumulative distributions of HFDs by treatment arm

2. Stacked bar plots and cumulative distributions of HFDs by time epochs 
medRxiv preprint doi: https://doi.org/10.1101/2021.09.03.21262551; this version posted September 9, 2021. The copyright holder for this preprint (which was not certified by peer review) is the author/funder, who has granted medRxiv a license to display the preprint in perpetuity.

All rights reserved. No reuse allowed without permission.

1590

3. Stacked bar plots and cumulative distributions of HFDs by sex

1591 


\section{The Variant Secondary analysis}

The following posterior probabilities will be reported for each time epoch

\begin{tabular}{|l|l|}
\hline Quantity of Interest & Posterior Probability \\
\hline B+E superior to B & \\
\hline B+E combination futile to B & \\
\hline C+I superior to B & \\
\hline C+I superior to B+E & \\
\hline
\end{tabular}

Statistical Triggers Met for Equivalence with delta ranges of equivalence

The following will be reported:

\begin{tabular}{|l|l|l|l|l|}
\hline $\begin{array}{l}\text { Odds-Ratio } \\
\text { Parameter }\end{array}$ & Mean & SD & Median & $\begin{array}{l}\text { 95\% Credible } \\
\text { Interval }\end{array}$ \\
\hline Age < 30 & & & & \\
\hline Age 30-39 & & & & \\
\hline Age 40-49 & & & & \\
\hline Age 50-59 & 1 & & & \\
\hline Age 60-69 & & & & \\
\hline Age 70-79 & & & & \\
\hline Age 80+ & & & & \\
\hline Female & & & & \\
\hline Time Bucket 1 & & & & \\
\hline$\ldots$ & & & & \\
\hline Time Bucket k-1 & 1 & & & \\
\hline Referent Arm & & & \\
\hline & For each time-epoch & \\
\hline Arm \#2 & & & & \\
\hline Arm \#3 & & & & \\
\hline Arm \#2/Arm \#3 & & & & \\
\hline
\end{tabular}

\section{Graphical summaries}

4. Stacked bar plots and cumulative distributions of HFDs by treatment arm by time epoch 


\section{References}

35. U.S. Food and Drug Administration News Release. Coronavirus (COVID-19) update: FDA authorizes monoclonal antibody for treatment of COVID-19. 2020 November 9. Available at: https://bit.ly/2HesBBs. Accessed July 20, 2021.

36. U.S. Food and Drug Administration. Fact sheet for health care providers emergency use authorization (EUA) of bamlanivimab. Available at: https://www.fda.gov/media/143603/download. Accessed July 20, 2021.

37. U.S. Food and Drug Administration. Fact sheet for health care providers emergency use authorization (EUA) of bamlanivimab and etesevimab. Available at: https://www.fda.gov/media/145802/download. Accessed July 20, 2021.

38. U.S. Food and Drug Administration. Fact sheet for health care providers emergency use authorization (EUA) of REGEN-COVTM. Available at: https://www.regeneron.com/downloads/treatment-covid19-eua-fact-sheet-for-hcp.pdf. Accessed July 20, 2021.

39. Angus D. Fusing Randomized trials with big data: the key to self-learning health care systems? JAMA 2015;314:767-8.

40. U.S. Department of Health \& Human Services. Monoclonal Antibodies: Updates from the Federal COVID Response. 2021 June 15. Available at https://leadingage.org/sites/default/files/ASPR_\%20AHCA_AMDA_LeadingAge\%20Monoc lonal\%20Webinar_20210615.pdf. Accessed July 20, 2021. 
Standard CONSORT with Pragmatic Trials Checklist

\begin{tabular}{|c|c|c|c|c|}
\hline Section & Item & Standard CONSORT Description & Pragmatic Trials Extension & Page \\
\hline Title and abstract & 1 & $\begin{array}{l}\text { How participants were allocated to } \\
\text { interventions (e.g., "random } \\
\text { allocation," "randomized," or } \\
\text { "randomly assigned") }\end{array}$ & & $1-4$ \\
\hline \multicolumn{5}{|l|}{ Introduction } \\
\hline Background & 2 & $\begin{array}{l}\text { Scientific background and explanation } \\
\text { of rationale }\end{array}$ & $\begin{array}{l}\text { Describe the health or health } \\
\text { service problem that the } \\
\text { intervention is intended to } \\
\text { address and other } \\
\text { interventions that may } \\
\text { commonly be aimed at this } \\
\text { problem }\end{array}$ & 5 \\
\hline \multicolumn{5}{|l|}{ Methods } \\
\hline Participants & 3 & $\begin{array}{l}\text { Eligibility criteria for participants; } \\
\text { settings and locations where the data } \\
\text { were collected }\end{array}$ & $\begin{array}{l}\text { Eligibility criteria should be } \\
\text { explicitly framed to show the } \\
\text { degree to which they include } \\
\text { typical participants and/or, } \\
\text { where applicable, typical } \\
\text { providers (e.g., nurses), } \\
\text { institutions (e.g., hospitals), } \\
\text { communities (or localities } \\
\text { e.g., towns) and settings of } \\
\text { care (e.g., different } \\
\text { healthcare financing systems) }\end{array}$ & $7-8$ \\
\hline \multirow[t]{2}{*}{ Interventions } & 4 & $\begin{array}{l}\text { Precise details of the interventions } \\
\text { intended for each group and how and } \\
\text { when they were actually administered }\end{array}$ & $\begin{array}{l}\text { Describe extra resources } \\
\text { added to (or resources } \\
\text { removed from) usual settings } \\
\text { in order to implement } \\
\text { intervention. Indicate if } \\
\text { efforts were made to } \\
\text { standardize the intervention } \\
\text { or if the intervention and its } \\
\text { delivery were allowed to vary } \\
\text { between participants, } \\
\text { practitioners, or study sites }\end{array}$ & - \\
\hline & & & $\begin{array}{l}\text { Describe the comparator in } \\
\text { similar detail to the } \\
\text { intervention }\end{array}$ & - \\
\hline Objectives & 5 & Specific objectives and hypotheses & & 5 \\
\hline Outcomes & 6 & $\begin{array}{l}\text { Clearly defined primary and secondary } \\
\text { outcome measures and, when } \\
\text { applicable, any methods used to } \\
\text { enhance the quality of measurements } \\
\text { (e.g., multiple observations, training of } \\
\text { assessors) }\end{array}$ & $\begin{array}{l}\text { Explain why the chosen } \\
\text { outcomes and, when relevant, } \\
\text { the length of follow-up is } \\
\text { considered important to those } \\
\text { who will use the results of } \\
\text { the trial }\end{array}$ & 8 \\
\hline Sample size & 7 & $\begin{array}{l}\text { How sample size was determined; } \\
\text { explanation of any interim analyses and } \\
\text { stopping rules when applicable }\end{array}$ & $\begin{array}{l}\text { If calculated using the } \\
\text { smallest difference } \\
\text { considered important by the } \\
\text { target decision maker }\end{array}$ & - \\
\hline
\end{tabular}




\begin{tabular}{|c|c|c|c|c|}
\hline Section & Item & Standard CONSORT Description & Pragmatic Trials Extension & Page \\
\hline & & & $\begin{array}{l}\text { audience (the minimally } \\
\text { important difference) then } \\
\text { report where this difference } \\
\text { was obtained }\end{array}$ & \\
\hline $\begin{array}{l}\text { Randomization- } \\
\text { sequence generation }\end{array}$ & 8 & $\begin{array}{l}\text { Method used to generate the random } \\
\text { allocation sequence, including details } \\
\text { of any restriction (e.g., blocking, } \\
\text { stratification) }\end{array}$ & & - \\
\hline $\begin{array}{l}\text { Randomization- } \\
\text { allocation } \\
\text { concealment }\end{array}$ & 9 & $\begin{array}{l}\text { Method used to implement the random } \\
\text { allocation sequence (e.g., numbered } \\
\text { containers or central telephone), } \\
\text { clarifying whether the sequence was } \\
\text { concealed until interventions were } \\
\text { assigned }\end{array}$ & & 6 \\
\hline $\begin{array}{l}\text { Randomization- } \\
\text { implementation }\end{array}$ & 10 & $\begin{array}{l}\text { Who generated the allocation sequence, } \\
\text { who enrolled participants, and who } \\
\text { assigned participants to their groups }\end{array}$ & & - \\
\hline Blinding (masking) & 11 & $\begin{array}{l}\text { Whether participants, those } \\
\text { administering the interventions, and } \\
\text { those assessing the outcomes were } \\
\text { blinded to group assignment }\end{array}$ & $\begin{array}{l}\text { If blinding was not done, or } \\
\text { was not possible, explain } \\
\text { why }\end{array}$ & 9 \\
\hline Statistical methods & 12 & $\begin{array}{l}\text { Statistical methods used to compare } \\
\text { groups for primary outcomes; methods } \\
\text { for additional analyses, such as } \\
\text { subgroup analyses and adjusted } \\
\text { analyses }\end{array}$ & & $9-11$ \\
\hline \multicolumn{5}{|l|}{ Results } \\
\hline Participant flow & 13 & $\begin{array}{l}\text { Flow of participants through each stage } \\
\text { (a diagram is strongly } \\
\text { recommended)-specifically, for each } \\
\text { group, report the numbers of } \\
\text { participants randomly assigned, } \\
\text { receiving intended treatment, } \\
\text { completing the study protocol, and } \\
\text { analyzed for the primary outcome; } \\
\text { describe deviations from planned study } \\
\text { protocol, together with reasons }\end{array}$ & $\begin{array}{l}\text { The number of participants or } \\
\text { units approached to take part } \\
\text { in the trial, the number which } \\
\text { were eligible, and reasons for } \\
\text { non-participation should be } \\
\text { reported }\end{array}$ & 12 \\
\hline Recruitment & 14 & $\begin{array}{l}\text { Dates defining the periods of } \\
\text { recruitment and follow-up }\end{array}$ & & - \\
\hline Baseline data & 15 & $\begin{array}{l}\text { Baseline demographic and clinical } \\
\text { characteristics of each group }\end{array}$ & & 12 \\
\hline Numbers analyzed & 16 & $\begin{array}{l}\text { Number of participants (denominator) } \\
\text { in each group included in each analysis } \\
\text { and whether analysis was by } \\
\text { "intention-to-treat"; state the results in } \\
\text { absolute numbers when feasible (e.g., } \\
10 / 20 \text {, not } 50 \% \text { ) }\end{array}$ & & 11 \\
\hline $\begin{array}{l}\text { Outcomes and } \\
\text { estimation }\end{array}$ & 17 & $\begin{array}{l}\text { For each primary and secondary } \\
\text { outcome, a summary of results for each }\end{array}$ & & 13 \\
\hline
\end{tabular}




\begin{tabular}{|c|c|c|c|c|}
\hline Section & Item & Standard CONSORT Description & Pragmatic Trials Extension & Page \\
\hline & & $\begin{array}{l}\text { group and the estimated effect size and } \\
\text { its precision (e.g., } 95 \% \mathrm{CI})\end{array}$ & & \\
\hline Ancillary analyses & 18 & $\begin{array}{l}\text { Address multiplicity by reporting any } \\
\text { other analyses performed, including } \\
\text { subgroup analyses and adjusted } \\
\text { analyses, indicating which are } \\
\text { prespecified and which are exploratory }\end{array}$ & & 13 \\
\hline Adverse events & 19 & $\begin{array}{l}\text { All-important adverse events or side } \\
\text { effects in each intervention group }\end{array}$ & & 13 \\
\hline \multicolumn{5}{|l|}{ Discussion } \\
\hline Interpretation & 20 & $\begin{array}{l}\text { Interpretation of the results, } \\
\text { considering study hypotheses, sources } \\
\text { of potential bias or imprecision, and the } \\
\text { dangers associated with multiplicity of } \\
\text { analyses and outcomes }\end{array}$ & & $14-16$ \\
\hline Generalizability & 21 & $\begin{array}{l}\text { Generalizability (external validity) of } \\
\text { the trial findings }\end{array}$ & $\begin{array}{l}\text { Describe key aspects of the } \\
\text { setting which determined the } \\
\text { trial results. Discuss possible } \\
\text { differences in other settings } \\
\text { where clinical traditions, } \\
\text { health service organization, } \\
\text { staffing, or resources may } \\
\text { vary from those of the trial }\end{array}$ & 16 \\
\hline Overall evidence & 22 & $\begin{array}{l}\text { General interpretation of the results in } \\
\text { the context of current evidence }\end{array}$ & & 17 \\
\hline
\end{tabular}

